\title{
Fibres from flax overproducing $\beta$-1,3-glucanase show increased accumulation of pectin and phenolics and thus higher antioxidant capacity
}

Wioleta Wojtasik ${ }^{1 \dagger}$, Anna Kulma ${ }^{1 *+}$, Lucyna Dymińska², Jerzy Hanuza ${ }^{2,3}$, Jacek Żebrowski ${ }^{4}$ and Jan Szopa ${ }^{1,5}$

\begin{abstract}
Background: Recently, in order to improve the resistance of flax plants to pathogen infection, transgenic flax that overproduces $\beta$-1,3-glucanase was created. $\beta$-1,3-glucanase is a PR protein that hydrolyses the $\beta$-glucans, which are a major component of the cell wall in many groups of fungi. For this study, we used fourth-generation fieldcultivated plants of the Fusarium -resistant transgenic line B14 to evaluate how overexpression of the B-1,3glucanase gene influences the quantity, quality and composition of flax fibres, which are the main product obtained from flax straw.

Results: Overproduction of $\beta-1,3-g$ lucanase did not affect the quantity of the fibre obtained from the flax straw and did not significantly alter the essential mechanical characteristics of the retted fibres. However, changes in the contents of the major components of the cell wall (cellulose, hemicellulose, pectin and lignin) were revealed. Overexpression of

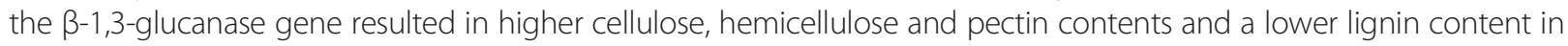
the fibres. Increases in the uronic acid content in particular fractions (with the exception of the $1 \mathrm{M} \mathrm{KOH}$-soluble fraction of hemicelluloses) and changes in the sugar composition of the cell wall were detected in the fibres of the transgenic flax when compared to the contents for the control plants. The callose content was lower in the fibres of the transgenic flax. Additionally, the analysis of phenolic compound contents in five fractions of the cell wall revealed important changes, which were reflected in the antioxidant potential of these fractions.
\end{abstract}

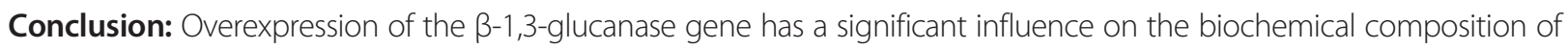
flax fibres. The constitutive overproduction of $\beta-1,3-$ glucanase causes a decrease in the callose content, and the resulting excess glucose serves as a substrate for the production of other polysaccharides. The monosaccharide excess redirects the phenolic compounds to bind with polysaccharides instead of to partake in lignin synthesis. The mechanical properties of the transgenic fibres are strengthened by their improved biochemical composition, and the increased antioxidant potential of the fibres supports the potential use of transgenic flax fibres for biomedical applications.

Keywords: Biopolymers, Fibres, Flax, Linum usitatissimum

\section{Background}

Flax (Linum usitatissimum) has been a valued crop plant throughout human history. Its main products are its oil and fibres, which are used in the pharmaceutical, cosmetic, food, paper and textile industries. In Poland, where there is a good climate for the growth of flax, cultivation has been limited in recent decades due to the

\footnotetext{
* Correspondence: kulma@ibmb.uni.wroc.pl

${ }^{\dagger}$ Equal contributors

${ }^{1}$ Faculty of Biotechnology, University of Wrocław, Przybyszewskiego 63/77,

51-148, Wrocław, Poland

Full list of author information is available at the end of the article
}

commercial competitiveness of cotton fibre and rapeseed oil. The renewal of its cultivation is significant because of the possibilities for its waste-free applications and its possible biomedical uses [1]. In parallel with this renewal, there has been a development of research into its genetic modification in order to improve the fibre and oil quality and increase the plants' resistance to pathogen infections.

Unlike the fibres of cotton, which are composed exclusively of cellulose, flax fibre is characterised by the presence of antioxidants. This makes it more valuable, giving it the potential to be used not only for textile manufacture, 
but also for the production of flax dressings and sutures [1]. Two major factors limit the yield of good quality flax fibres: any decline in plant productivity caused by infections; and the dependence of the retting process on external and internal conditions, such as the weather, the lignification of the plant cell wall, and the pectin and hemicellulose contents of the fibre.

The flax retting process involves the separation of flax fibres from the epidermis and the cortical part of the stalk through pectin and hemicellulose degradation by microorganisms. The most common method of retting is the dew method, which involves flax decomposition in the field, with fungi and bacteria degrading the polysaccharides in the cell walls of the stalks [2].

Pectin is a polysaccharide with galacturonic acid residues constituting up to $70 \%$ of its overall structure. It consists of four pectin domains: homogalacturonan (HGA), rhamnogalacturonan I (RGI), rhamnogalacturonan II (RGII) and xylogalacturonan (XGA). Pectin plays a significant role in both plant physiology and plant defence against pathogen infection, as it constitutes a structural barrier to attack by fungi $[3,4]$. The quantitative and qualitative contribution of pectin to the construction of the plant cell wall depends on the plant species, so there are various possible consequences of modifications of pectin metabolism in various species [5].

Lignification of the cell walls in stalks is also a relevant issue for retting and thus for fibre quality. Flax intended for fibre production is harvested on day 107 of plant growth to prevent too great a degree of cell wall lignification. In order to improve the yield of flax, research is focused on generating transgenic flax plants that are more resistant to specific pathogens but characterised by unchanged or improved productivity relative to nonmodified plants. Studies have shown that genetically modified flax with higher contents of certain constituents also has the potential to become a source of innovative products with biomedical properties.

Pathogen infections cause large loses in the yield from flax cultivation. Varieties of plants that are more resistant to infection have been generated through the introduction of genes for secondary metabolite synthesis or PR genes [6-11].

Plant $\beta$-1,3-glucanases are pathogenesis-related proteins classified as members of the PR-2 family. They are constitutively expressed at low levels, but their expression dramatically increases during infection. $\beta$-1,3-glucanase hydrolyses $\beta$-1,3-glucans, which are the main components of the cell wall of fungi. It acts in at least two different ways: directly, by degrading the cell walls of the pathogen; and indirectly, by promoting the release of cell wallderived materials that can act as elicitors of defence reactions, stimulating the production of other PR proteins or low molecular weight antifungal compounds, such as phytoalexins [12,13]. By degrading callose, $\beta-1,3$-glucanases are also involved in various physiological and developmental processes, namely cell elongation [14], cell division [15], fruit ripening [16], fertilization [17], pollen germination and tube growth [18], bud dormancy release [19], microsporogenesis [20], somatic embryogenesis [21], seed germination [22,23] and flower formation [24,25]. Callose is a linear homopolymer that consists of glucose residues linked by $\beta-1,3$ binding with some $\beta-1,6$ branches, and it is widespread in higher plants [26].

Recently, in order to improve the resistance of flax to pathogen infection, we generated a transgenic plant that overexpresses $\beta-1,3$-glucanase. The resulting transgenic flax (named type B) was characterised by a threefold increase in resistance to Fusarium oxysporum and F. culmorum infection. In vitro-cultivated type B plants also displayed a significant decrease in the contents of carbohydrates, fatty acids and organic acids, and an increase in the levels of selected amino acids, polyamines and antioxidants [27].

The aim of this study was to investigate the influence of the constitutively expressed $\beta$-1,3-glucanase in flax type $\mathrm{B}$ on the biochemical composition of the cell wall and the mechanical properties of flax fibres in order to establish the usefulness of this transgenic plant for textile and pharmaceutical production. Of particular interest to us were the polysaccharide composition (pectin and hemicellulose) and the phenolic compound contents of the flax fibres. It was also important to analyse whether the overproduction $\beta$-1,3-glucanase could affect the quantity and the composition of the fibres obtained from the straw.

\section{Results}

Fibre quantity

The usability of flax fibre depends on the efficiency of the retting process. The transgenic flax line B14 and the non-transgenic flax line Nike gave similar yields of fibre from their straw (Figure 1). This indicates that the overexpression of the $\beta$-1,3-glucanase gene in flax had no influence on the quantity of the isolated fibre.

\section{Major cell wall structural components}

Cellulose, hemicellulose, pectin and lignin are the major structural components of the plant cell wall. Cellulose, a linear polysaccharide consisting of $\beta$-1,4-linked D-glucose units, is the core of the plant cell wall, serving as a scaffold for the other cell wall components. Hemicellulose, a heteropolymer of polysaccharides, is divided into several classes: xyloglucans, glucomannans, glucuronoarabinoxylans and mixed linkage glucans [28]. Lignins are large, complex polymers of three principal alcohols: coniferyl, sinapyl and p-coumaryl [29].

The amounts of those components were determined in fibres from transgenic flax line B14 and a control, 


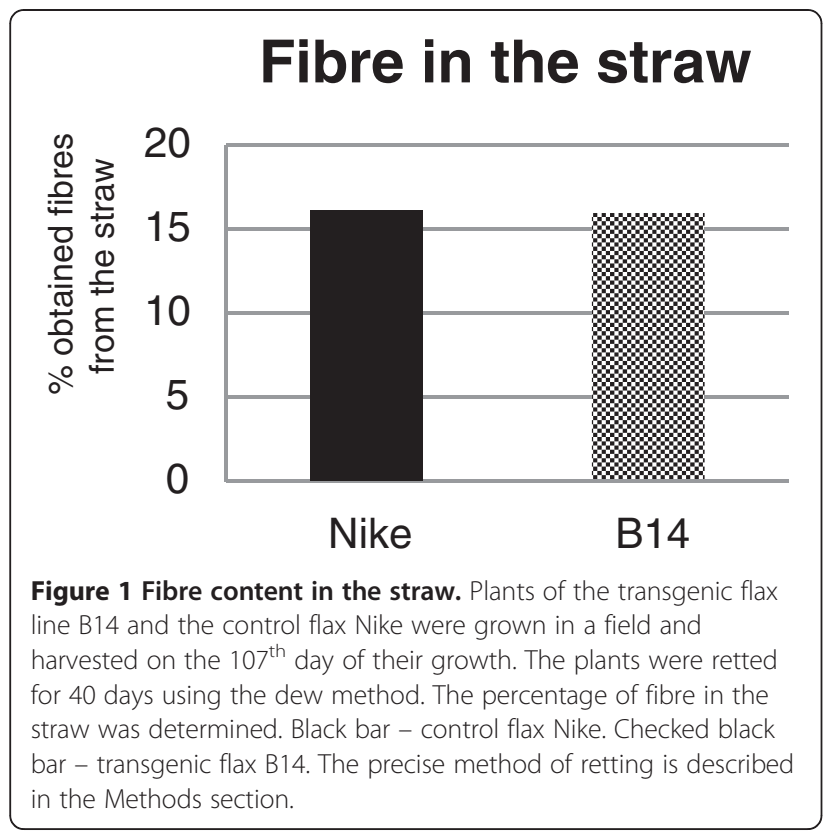

non-transgenic flax line (Nike). The results are presented in Figure 2. The cellulose content was only slightly higher in fibres from B14 flax. However, the lignin level was significantly lower in fibres from B14 flax. The pectin and hemicellulose contents were higher in the fibres of the transgenic flax than in those of the control and these differences were statistically significant.

The transgenic flax plants overexpressing the $\beta$-1,3-glucanase gene were characterised by alterations in the composition of the cell wall. The higher cellulose content could indicate improved mechanical properties. The reduced lignin content could give better elastic properties and higher fibre flexibility. Additionally, the lower degree of lignification has a positive effect on the retting process, increasing its efficiency. However, the higher pectin content may have compensated for the lower lignin content and may be the reason that the efficiency of retting process was unchanged. No in vitro experiment on straw retting was performed, but the observed field retting time for the transgenic flax did not differ from that for the control.

\section{Infra-red spectrophotometry analysis}

The IR spectra of the fibres from the Nike and B14 plants are presented in Figure 3A. Four characteristic ranges can be distinguished: 2500-4000, 1400-1800, $900-1400$ and $400-900 \mathrm{~cm}^{-1}$. The main contours are similar to those reported for other flax fibres [30-33]. However, the relative intensities of several narrow lines that appear on the slope of these broad bands lead to an important conclusion on the chemical content of the transgenic flax. The IR spectra of the fibres from the control and genetically modified flax mainly consist of the bands that are characteristic for cellulose [30-36].

The broad absorption band at $3400 \mathrm{~cm}^{-1}$ corresponds to the stretching $v(\mathrm{OH})$ mode of the free hydroxyl groups and those involved in intra- and inter-molecular hydrogen bonds [37]. The shape of this band is nearly the same for all of the studied samples, but the bands differ in terms of their absorption intensity (Figure 3B). The intensity of the contour in the range from 3000 to $3600 \mathrm{~cm}^{-1}$ clearly increases for fibres from B14 flax. This
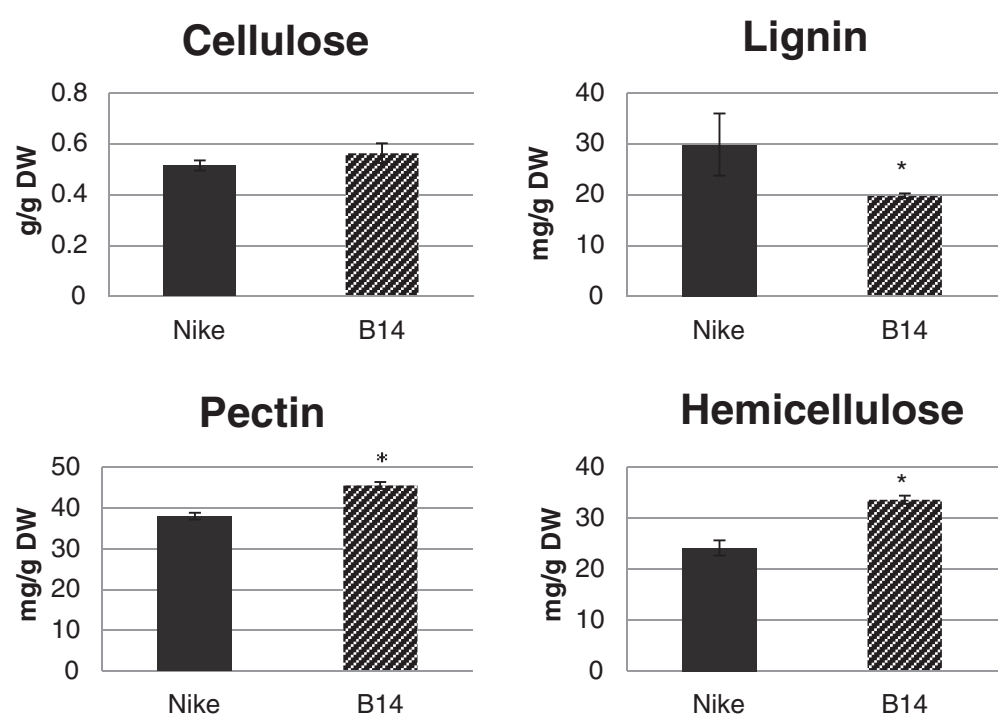

Figure 2 Contents of major cell wall components. The cellulose, lignin, pectin and hemicellulose contents were measured in the fibres of the transgenic flax line B14 (striped black bar) and the non-transgenic control flax Nike (black bar). Analyses were performed as described in the Methods section. Data represent the mean values \pm SD from four independent experiments. The significance of the differences between the means was determined using Student's $t$ test $\left(^{*}-P<0.05,^{* *}-P<0.01\right)$. 


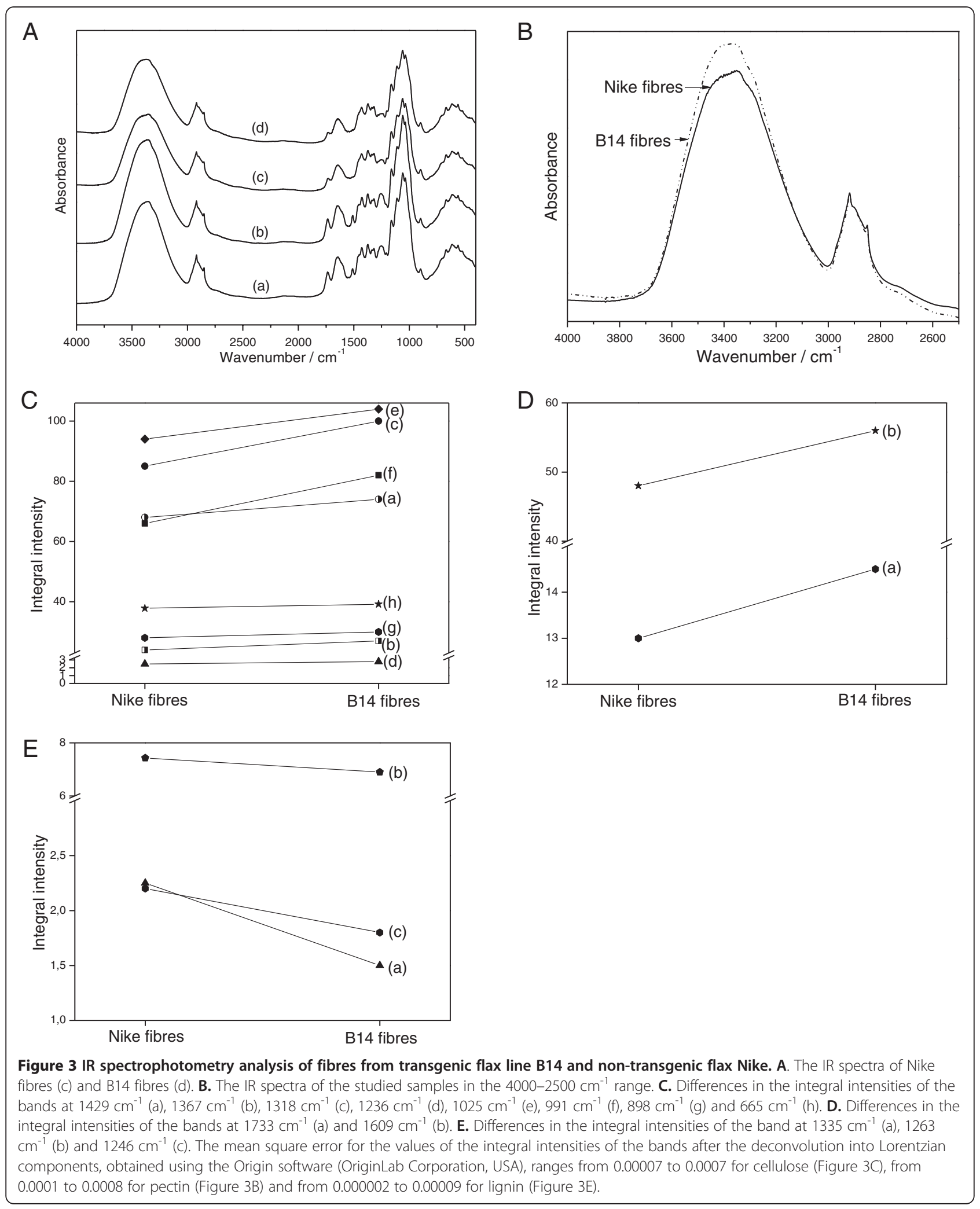


is probably caused by different conformations of the intra- and inter-molecular $\mathrm{O}-\mathrm{H} \ldots \mathrm{O}$ hydrogen bonds in the B14 samples. The contours observed in the IR spectra of the flax fibres in the ranges $1500-1200 \mathrm{~cm}^{-1}$, $1200-950 \mathrm{~cm}^{-1}$ and $950-500 \mathrm{~cm}^{-1}$ are typical for flax cellulose with some amounts of lignin and pectin. The bands in these multiplets can be assigned to the vibration of $\delta_{\text {as }}\left(\mathrm{CH}_{3}, \mathrm{CH}_{2}\right)$ at $1429 \mathrm{~cm}^{-1}, \delta_{\mathrm{s}}\left(\mathrm{CH}_{3}, \mathrm{CH}_{2}\right)$ at about $1372 \mathrm{~cm}^{-1}, \delta(\mathrm{CH})$ at 1319 and $1336 \mathrm{~cm}^{-1}, v(\mathrm{C}-\mathrm{C})$ and $v(\mathrm{C}-\mathrm{O})$ in the range $1200-1300 \mathrm{~cm}^{-1}, \delta(\phi-\mathrm{OH})$ at 1163 $\mathrm{cm}^{-1}, v_{\text {as }}(\mathrm{C}-\mathrm{O}-\mathrm{C})$ in the range $1000-1110 \mathrm{~cm}^{-1}, \gamma(\mathrm{CH})$ in the range $850-1000 \mathrm{~cm}^{-1}$, and $\delta(\theta)$ in the range $500-720$ $\mathrm{cm}^{-1}$. The spectrum in the $1200-1300 \mathrm{~cm}^{-1}$ range consists of a strong multiplet that is characteristic of in-plane bending vibrations of the hydrogen bond, $\delta(\mathrm{OH} \ldots \mathrm{O})$. Integral intensities of the component at $1236 \mathrm{~cm}^{-1}$ increase for fibres from B14 (8\%) relative to fibres from Nike, suggesting an increase in the hydrogen bond number in the transgenic fibres. Other bands at 1318 and $1429 \mathrm{~cm}^{-1}$ respectively correspond to the $\delta(\mathrm{CH})+\delta(\mathrm{OH})$ and $\delta_{\mathrm{as}}\left(\mathrm{CH}_{2}, \mathrm{CH}_{3}\right)$ vibrations. The comparison of the integral intensities of these bands gives the following relationships: for the $1429 \mathrm{~cm}^{-1}$ band $\mathrm{I}_{\mathrm{B} 14}$ fibres $>\mathrm{I}_{\text {Nike fibres }}\left(24.2 \%\right.$ difference) and for the $1318 \mathrm{~cm}^{-}$ 1 band $\mathrm{I}_{\mathrm{B} 14}$ fibres $>\mathrm{I}_{\text {Nike fibres }}(17.6 \%$ difference; Figure 3C). The band at about $1367 \mathrm{~cm}^{-1}$ was described as cellulose and hemicellulose absorbance. Its integral intensities are higher for fibres from B14 (12.5\% increase) than for those from Nike. The bands at 1025 and $991 \mathrm{~cm}^{-1}$ originate from the $v(\mathrm{COC})$ vibrations of the $\beta$ 1,4-glycosidic bond of the cellulose chains. The integral intensities analysed for these bands show the trend $\mathrm{I}_{\mathrm{B} 14}$ $>\mathrm{I}_{\text {Nike }}$. This difference is $10.6 \%\left(1025 \mathrm{~cm}^{-1}\right)$ and $8.8 \%$ (991 $\mathrm{cm}^{-1}$; Figure 3C). The weak band at $898 \mathrm{~cm}^{-1}$ corresponds to vibrations of cellulose. The integral intensity for this band is slightly higher for fibres from B14 than for those from Nike (7.4\%). The integral intensities of the band at $665 \mathrm{~cm}^{-1}$ corresponding to the $\gamma(\mathrm{OH} \cdots \mathrm{O})$ vibration also change [37]. They are higher for fibres from B14 (5.3\%). All these data suggest a higher amount of cellulose and hemicellulose in fibres from B14 than in those from Nike, which agrees with a chemical analysis data.

The IR bands in the $1800-1500 \mathrm{~cm}^{-1}$ range may be used to identify the changes in the pectin content in the fibres from the control and transgenic flax. IR spectra in this range can be deconvoluted into three Lorentzian components. The component at about $1737 \mathrm{~cm}^{-1}$ corresponds to the $v_{\mathrm{as}}(\mathrm{COO})$ vibrations of the unconjugated carboxyl group of pectin. The integral intensity of this band fulfils the relationship $\mathrm{I}_{\text {Nike fibres }}<\mathrm{I}_{\mathrm{B} 14}$ fibres, showing that transgenic flax B14 exhibits higher contents of pectin. This difference comes to $11.5 \%$ (Figure 3D). The position of the band at $1655 \mathrm{~cm}^{-1}$ corresponds to the $v_{\text {as }}$
(COO) vibration of the conjugated carboxyl group [38]. Its intensity slightly increases for fibres from transgenic flax. The third band, which appears at about $1605 \mathrm{~cm}^{-1}$, corresponds to the $v_{\mathrm{s}}(\mathrm{COO})$ vibrations of the carboxyl group present in pectin. The strongest integral intensity is observed for fibres from B14 flax. The difference comes to $16.6 \%$ (Figure 3D). These data show that the content of pectin increases in fibres of transgenic flax line B14.

The IR bands in the $1300-1200 \mathrm{~cm}^{-1}$ range may be used to identify the changes in lignin content in the fibres from the control and transgenic flax. It can be deconvoluted into four Lorentzian components. The components at about 1263 and $1246 \mathrm{~cm}^{-1}$ correspond to lignin vibrations [37]. The integral intensities of these bands decrease for B14 fibres $(7.13 \%$ and $14 \%$ for the bands at $1263 \mathrm{~cm}^{-1}$ and $1246 \mathrm{~cm}^{-1}$, respectively) suggesting a decrease in the lignin content in the B14 fibres (Figure 3E). Useful information can be obtained by comparing the integral intensities of the band observed at about $1325 \mathrm{~cm}^{-1}$, which corresponds to $v(\phi)$ ( $\phi$-ring) vibration. The intensities of this band fulfil the relationship $\mathrm{I}_{\mathrm{B} 14 \text { fibres }}<\mathrm{I}_{\text {Nike fibres. }}$. These data show that the lignin content is lower in the flax fibres of transgenic line B14 than in those from the control flax confirming the results obtained by chemical analysis.

\section{Mechanical properties}

Overexpression of $\beta$-1,3-glucanase did not significantly alter the essential mechanical characteristics of the retted fibres, including their tensile strength, tensile stiffness, energy to break and relative extension at break (Figure 4). However, a statistically non-significant reduction was observed in Young's modulus and the energy to break for fibres from transgenic flax line B14 relative to the values for the control, non-transgenic flax.

Despite some changes in the carbohydrate and lignin contents, the effect of introducing the $\beta$-1,3-glucanase gene on the load-bearing performance of the fibre cell wall and thus that of the retted fibres was rather negligible. That may be explained by the compensating impact of the various biochemical changes observed in the transgenic plants.

\section{Uronic acid content in the cell wall fractions}

During fractionation of the cell wall material, three fractions of pectin were obtained: the water-soluble fraction (WSF - pectin that is loosely associated with the cell wall); the CDTA-soluble fraction (CSF - pectin that is enriched in bound ions); and the $\mathrm{Na}_{2} \mathrm{CO}_{3}$-soluble fraction (NSF - pectin that is enriched in covalently bound ions). Two fractions of hemicellulose were also obtained: the $1 \mathrm{M} \mathrm{KOH}$-soluble fraction (K1SF) and the $4 \mathrm{M}$ $\mathrm{KOH}$-soluble fraction (K4SF). The content of uronic 


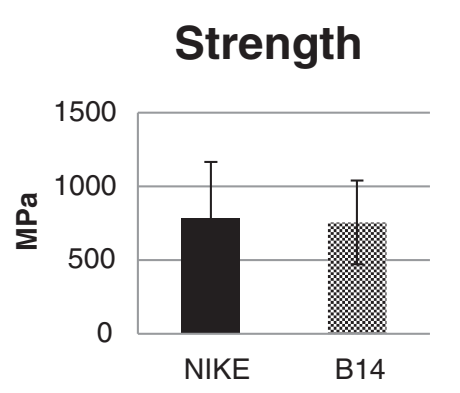

\section{Energy to break}

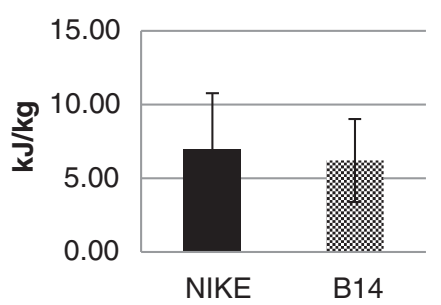

Young's modulus

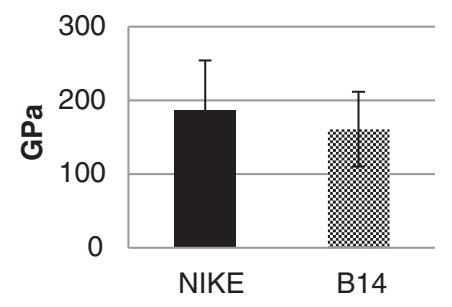

Elongation at break

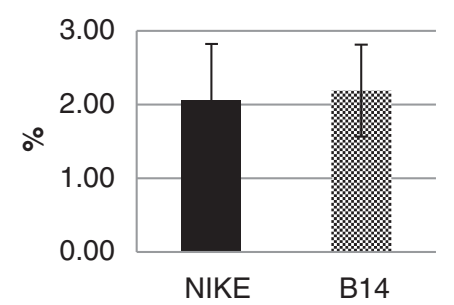

Figure 4 Mechanical property analysis of flax fibres. Four major mechanical parameters were measured for the retted fibres of transgenic line B14 (checked bar) and control flax Nike (black bar): tensile strength, tensile stiffness (Young's modulus), energy to break, and relative extension at break. Analyses were performed as described in the Methods section. The mean values \pm SD are presented $(n=30)$.

acids (mainly galacturonic acid) was determined using spectrophotometry, as described in the Methods section. The data are presented in Figure 5.

The results obtained from the three fractions of pectin (WSF, CSF and NSF) revealed an increase in the uronic acid content in the fibres of transgenic line B14 compared to the values for the non-transgenic flax fibres. Statistically significant changes were observed in the CSF and NSF, whereas only a slight, non-significant increase was detected in the WSF. Galacturonic acid is the main component of pectic polysaccharides, so the CSF, which contains the highest amount of GalAc $(14.5 \mathrm{mg} / \mathrm{g}$ DW), can be called the key fraction of a flax pectin.

The data obtained for the two hemicellulose fractions revealed a significant decrease in the uronic acid content in fibres from transgenic flax line B14 in K1SF and a significant increase in the fibres from transgenic flax in K4SF compared to the values for the control fibres.

\section{Monosaccharide composition in cell wall fractions}

The monosaccharide compositions of the three fractions of pectin (WSF, CSF and NSF) and the two fractions of hemicellulose (K1SF and K4SF) were analysed by UPLC. Figure 6 shows the statistically significant increase in glucose content in the three fraction of pectin in the fibres of transgenic line B14 relative to the contents for the control fibres The amount of galactose, the other major sugar, is increased in all the pectin fractions, but these changes were statistically insignificant. The only other sugar significantly changed in WSF fraction was ribose present however on a very low level. The more significant changes were observed for CSF fraction where increase in mannose and arabinose and decrease in xylose were found statistically significant. For NSF fraction statistically significant increase in mannose and xylose and lowering of rhamnose was observed.

Similarly the increase in glucose content was observed in hemicellulose fractions however those changes were statistically significant only for K1SF fractions. The mannose contents were significantly higher and rhamnose, arabinose and ribose significantly lower in K1SF fraction of the fibres from transgenic flax. A statistically significant increase in xylose and fucose content was found in the hemicellulose K4SF of the fibres of transgenic line B14 relative to the values for the non-transgenic plants. There were noticeable similarities in the changes in the contents of particular monosaccharides in the pectin and hemicellulose fractions. To better illustrate the changes in a pectin and hemicellulose composition the molar participation of particular monosaccharides in the pectin and hemicellulose fractions was calculated and is presented in Table 1 . There are some significant differences between the monosaccharide composition of all of the fractions in the fibres of transgenic line B14 and the composition of the fibres of the control flax, mostly coinciding with the data presented as the quantity of monosaccharides (in $\mathrm{mg}$ of sugar per $\mathrm{g}$ of fibre). The most notable exception is in mannose whose molar ratio 

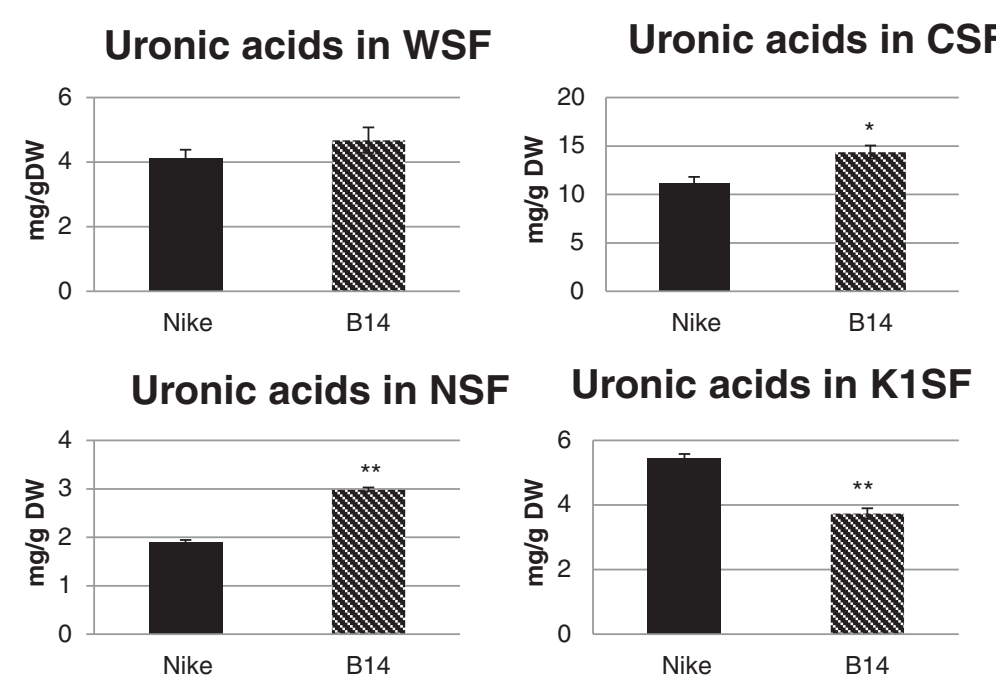

\section{Uronic acids in K4SF}

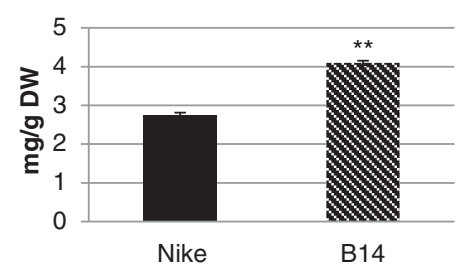

Figure 5 Uronic acid contents in the cell wall fractions. The uronic acid contents in five cell wall fractions (WSF - water-soluble fraction, CSF - CDTA-soluble fraction, NSF - $\mathrm{Na}_{2} \mathrm{CO}_{3}$-soluble fraction, K1SF - $1 \mathrm{M} \mathrm{KOH}$-soluble fraction and K4SF - $4 \mathrm{M} \mathrm{KOH}$-soluble fraction) were determined for fibres from transgenic flax line B14 (striped black bar) and non-transgenic control flax Nike (black bar). Analyses were performed as described in the Methods section. Data represents the mean values \pm SD from three independent experiments. The significance of the differences between the means was determined using Student's t test $\left(^{*}-P<0.05\right.$, * $\left.-P<0.01\right)$.

to other sugars is not statistically changed in all fractions except K1SF even though its general level is increased. The strongest and statistically significant changes in composition are observed for fractions NSF and K4SF. The data also confirmed that CSF is the main fraction of pectin, because its galacturonic acid content is higher than the content of other monosaccharides. K1SF and K4SF contain a considerable amount of xyloglucans compared to the pectin fractions.

\section{Flax fibre callose content}

Callose contents were determined using spectrofluorometry with $\beta$-1,3-glucan as the standard for preparing the calibration curve. The callose content was reduced in the fibres from transgenic flax B14 relative to that of the control flax fibres. The difference in the compound content came to $20 \%$ and was statistically significant (Figure 7).

Phenolic acid, phenolic aldehyde and vitexin contents in the cell wall fractions of the cell wall

Phenolic acids (vanillic acid, coumaric acid and ferulic acid), phenolic aldehydes (syringic aldehyde and vanillin) and vitexin (C-glucosylated flavone) were detected in all of the cell wall fractions after alkaline hydrolysis, which indicated an ester bond with the monosaccharides that compose the pectin and hemicelluloses in the cell wall (Table 2). A statistically significant increase in the contents of vanillin, ferulic acid and vitexin, and a statistically non-significant increase in the contents of vanillic acid, coumaric acid and syringic aldehyde were detected in the CSF of the fibres from transgenic line B14 compared to the values for the control flax fibres. Slightly reduced levels of vanillic acid, coumaric acid and syringic aldehyde and slightly increased levels of ferulic acid, vanillin and vitexin were found in the WSF of the fibres from the transgenic flax. A significantly lower level of vanillic acid and syringic aldehyde and a lack of changes in the levels of the rest of phenolic compounds were detected in the NSF from the transgenic flax. The levels of all of the phenolic compounds with the exception of vitexin increased significantly in the hemicellulose K4SF and slightly in the hemicellulose K1SF of the fibres from transgenic flax compared to the levels for the non-transgenic plants. In the K1SF, the increases for 

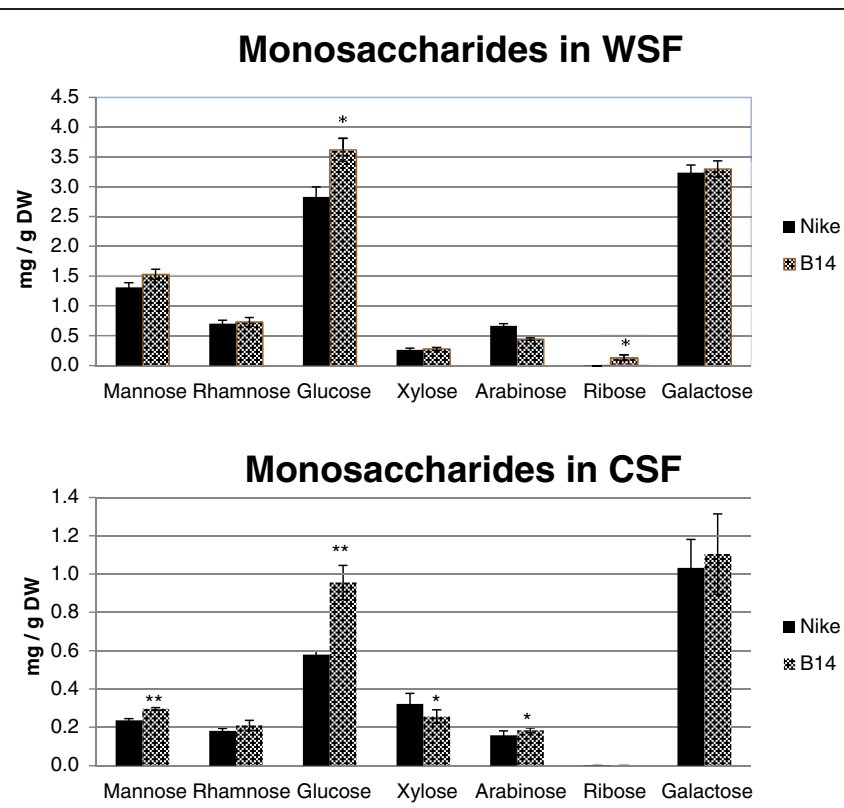

Monosaccharides in NSF

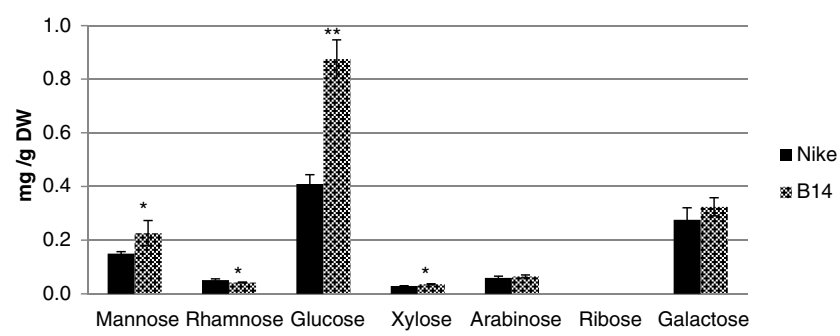

Monosaccharides in K1SF
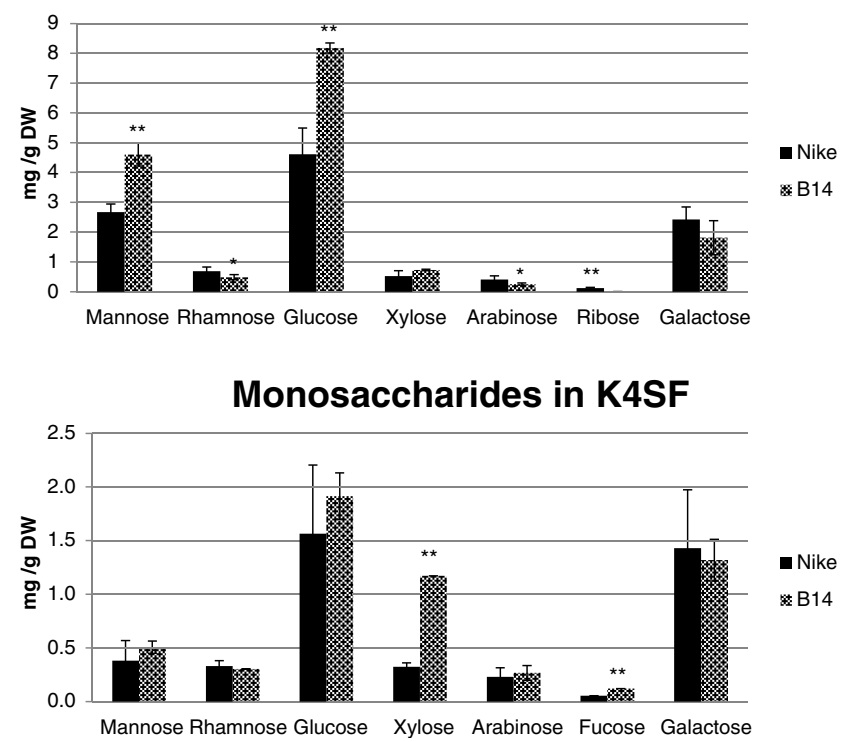

Figure 6 (See legend on next page.) 
(See figure on previous page.)

Figure 6 Monosaccharide composition in the cell wall fractions. UPLC analysis was performed of the monosaccharide contents in the cell wall fractions (WSF - water-soluble fraction, CSF - CDTA-soluble fraction, NSF - $\mathrm{Na}_{2} \mathrm{CO}_{3}$-soluble fraction, $\mathrm{K} 1 \mathrm{SF}-1 \mathrm{M} \mathrm{KOH}$-soluble fraction and K4SF - $4 \mathrm{M} \mathrm{KOH}$-soluble fraction) for fibres from transgenic flax line B14 (checked black bar) and non-transgenic control flax Nike (black bar). Analyses were performed as described in the Methods section. Data represents the mean values \pm SD from three independent experiments. The significance of the differences between the means was determined using Student's $t$ test $\left({ }^{*}-P<0.05,{ }^{* *}-P<0.01\right)$.

coumaric acid, ferulic acid and vitexin were statistically significant.

The content of phenolic compounds expressed as mmol per $100 \mathrm{~mol}$ of monosaccharides in the various cell wall fractions are shown in Table 3, giving a sense of the stoichiometry of the components of the analysed fractions. The highest level of phenolic compounds was measured in the hemicellulose K1SF in both the transgenic and control fibres. The calculated molar stoichiometry of phenolics and monosaccharides reveals that the hemicellulose K4SF accumulates a statistically significant excess of phenolic compounds detected in transgenic fibres. Vanillin and vanillic and phenolic acids were predominantly detected in this fraction. Since the monosaccharide content of the K4SF from both of the analysed fibre types differs mainly in terms of the xylose content, we speculate that this sugar unit is predominantly esterified by phenolic acids in the transgenic fibre. However, this needs to be verified.

\section{Antioxidant activity}

The antioxidant activities of particular cell wall fractions were determined using the DPPH method. The free radical 2.2-diphenyl-1-picrylhydrazyl (DPPH•) is scavenged by antioxidants, and the percentage of inhibition could be measured as the decrease in absorbance at $515 \mathrm{~nm}$. The scavenging activity of the pectin and hemicellulose fractions at a concentration of $5 \mathrm{mg} / \mathrm{ml}$ was compared with that of commercially available pectin at the same concentration (Figure 8). The antioxidant activity of commercial pectin was the lowest (5-7\%). The percentage of inhibition of free radicals for the three pectin fractions (WSF, CSF and NSF) was between 12 and $15 \%$. The antioxidant potential for transgenic fibre B14 was lower than that of the control, but these changes were statistically insignificant. The highest antioxidant potential was observed for the K1SF: from 23\% inhibition for the control fibres and 27\% for the B14 transgenic fibres. The K4SF displays an increase in antioxidant activity for the transgenic flax fibre (11\% inhibition of free radicals) relative to the control flax fibre (6\%). These data indicate that the hemicellulose K1SF has the best antioxidant potential, which correlates with the phenolic compound content (Table 3).

\section{Discussion}

Flax (Linum usitatissimum) is a valuable source of oil rich in omega- 3 fatty acids (mainly linolenic acid) and fibres containing antioxidant compounds. Flax fibres are mainly used by the textile industry, but the presence of valuable bioactive compounds means there is potential for biomedical applications as wound dressings and sutures [1].

The production of high-quality flax fibres is limited by several factors, such as plant productivity, the efficiency of straw processing (retting) and the contents and stoichiometry of biopolymers (cellulose, hemicellulose,

Table 1 Molar composition of monosaccharides in the cell wall fractions

\begin{tabular}{|c|c|c|c|c|c|c|c|c|c|c|}
\hline \multicolumn{11}{|c|}{ Monosaccharide (mol/100 mol of total sugars) } \\
\hline Fraction & & Man & Rha & Glc & Xyl & Ara & Fuc & Rib & Gal & GalAc \\
\hline \multirow[t]{2}{*}{ WSF } & Nike & $10.04 \pm 0.87$ & $5.88 \pm 0.35$ & $21.65 \pm 0.63$ & $2.38 \pm 0.22$ & $6.01 \pm 0.31$ & 0 & 0 & $24.80 \pm 0.89$ & $29.33 \pm 1.63$ \\
\hline & B14 & $10.41 \pm 1.10$ & $5.47 \pm 0.61$ & $24.67 \pm 0.39^{*}$ & $2.27 \pm 0.43$ & $3.65 \pm 1.08$ & 0 & $1.67 \pm 0.21$ & $22.62 \pm 1.22$ & $29.62 \pm 2.25$ \\
\hline \multirow[t]{2}{*}{ CSF } & Nike & $1.83 \pm 0.10$ & $1.54 \pm 0.07$ & $4.50 \pm 0.25$ & $2.99 \pm 0.57$ & $1.47 \pm 0.21$ & 0 & $1.06 \pm 0.24$ & $7.96 \pm 1.18$ & $78.80 \pm 2.47$ \\
\hline & B14 & $1.79 \pm 0.41$ & $1.39 \pm 0.20$ & $5.75 \pm 0.51^{* *}$ & $1.85 \pm 0.26^{* *}$ & $1.33 \pm 0.11$ & 0 & 0 & $6.70 \pm 1.34$ & $80.97 \pm 2.15$ \\
\hline \multirow[t]{2}{*}{ NSF } & Nike & $5.56 \pm 0.36$ & $2.16 \pm 0.05$ & $14.78 \pm 1.43$ & $1.26 \pm 0.08$ & $2.56 \pm 0.27$ & 0 & 0 & $9.45 \pm 0.83$ & $65.07 \pm 0.64$ \\
\hline & B14 & $5.50 \pm 1.71$ & $1.11 \pm 0.06^{* *}$ & $20.77 \pm 1.39^{* *}$ & $1.02 \pm 0.04^{* *}$ & $1.85 \pm 0.22^{* *}$ & 0 & 0 & $7.40 \pm 0.86^{*}$ & $67.41 \pm 3.80$ \\
\hline \multirow[t]{2}{*}{ K1SF } & Nike & $15.76 \pm 0.94$ & $4.45 \pm 0.65$ & $26.99 \pm 2.65$ & $3.78 \pm 1.38$ & $3.04 \pm 0.60$ & 0 & $0.76 \pm 0.18$ & $14.68 \pm 1.30$ & $29.29 \pm 3.47$ \\
\hline & B14 & $23.17 \pm 0.83^{* *}$ & $2.74 \pm 0.51^{* *}$ & $41.01 \pm 6.01^{* *}$ & $4.44 \pm 0.42$ & $1.58 \pm 0.23^{* *}$ & 0 & $0^{*}$ & $9.48 \pm 3.29^{*}$ & $17.53 \pm 1.84^{* *}$ \\
\hline \multirow[t]{2}{*}{ K4SF } & Nike & $6.71 \pm 0.39$ & $4.97 \pm 0.58$ & $22.30 \pm 8.84$ & $5.34 \pm 0.39$ & $3.76 \pm 1.26$ & $0.87 \pm 0.04$ & 0 & $20.42 \pm 7.51$ & $36.65 \pm 2.40$ \\
\hline & $\overline{B 14}$ & $5.19 \pm 0.74$ & $3.41 \pm 0.13$ & $19.92 \pm 1.62$ & $14.38 \pm 0.41^{* *}$ & $2.93 \pm 0.59$ & $1.46 \pm 0.14$ & 0 & $12.59 \pm 0.01$ & $39.62 \pm 1.14$ \\
\hline
\end{tabular}

The amount of mol of the studied monosaccharides to 100 mol of monosaccharides in the cell wall fractions (WSF - water-soluble fraction, CSF - CDTA-soluble fraction, NSF - $\mathrm{Na}_{2} \mathrm{CO}_{3}$-soluble fraction, $\mathrm{K} 1 \mathrm{SF}-1 \mathrm{M} \mathrm{KOH}$-soluble fraction and K4SF - $4 \mathrm{M} \mathrm{KOH}$-soluble fraction) for fibres from transgenic flax line B14 and the non-transgenic control flax Nike. Man - mannose, Rha - rhamnose, Glc - glucose, Xyl - xylose, Ara - arabinose, Fuc- fucose, Rib - ribose, Gal - galactose and GalAc - galacturonic acid. Data represents the mean values \pm SD from three independent experiments. The significance of the differences between the means was determined using Student's test $(*-P<0.05, * *-P<0.01)$. 


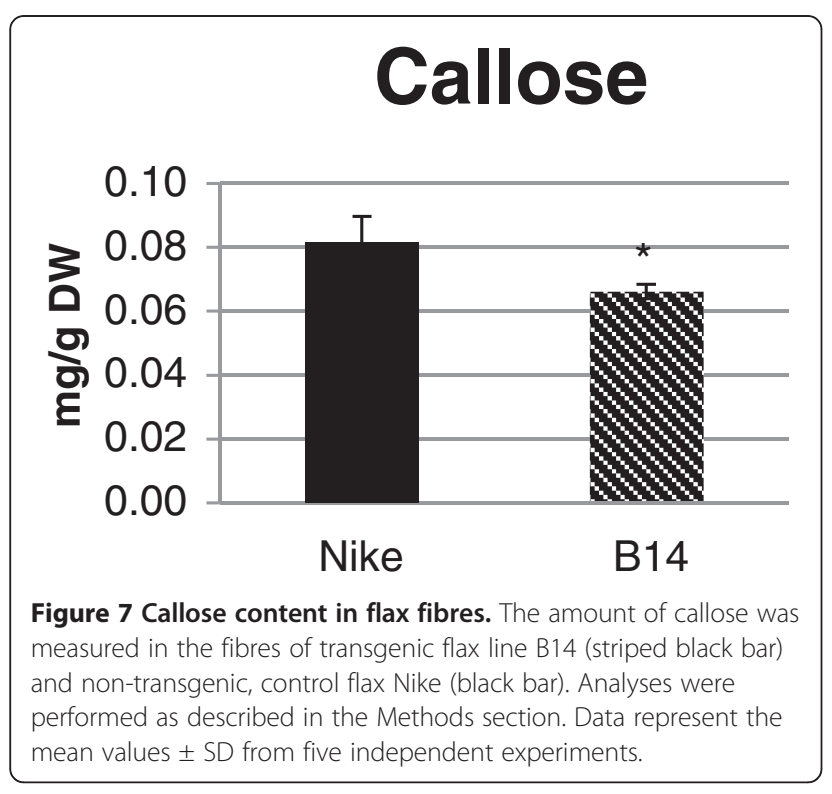

pectin, lignin). The productivity of flax depends on abiotic (climate) and biotic (pathogens) factors. In our previous study, in order to improve productivity, flax plants with overexpression of the $\beta$-1,3-glucanase gene were generated and characterised by the increase in resistance to fungal infection [27]. This effect was expected because $\beta-1,3$-glucanase is responsible for the hydrolysis of $\beta-1,3-$ glucans, the main compound of the fungal cell wall [25].

The aim of this study was to assess the fibres of fourth generation plants of this transgenic line that had been field-cultivated on a semi-technical scale in the 2010 growing season. The rationale behind the study was that fibre polysaccharides determine the technological properties of fibres and their industrial usefulness. $\beta$-1,3-glucanase is capable of endogenous $\beta$-1,3-glucan (callose) degradation and glucose derivatives are the main constituents of fibre polysaccharides, so the transgenic plants should display different properties.

There were no changes in the fibre yield from the transgenic flax that overproduces $\beta$-1,3-glucanase compared to the yield from the control plants. However, there were significant differences in both the quantity and quality of the main biopolymers that constitute the fibre. The genetic modification resulted in a slight increase in the cellulose content, a statistically significant increase in the pectin and hemicellulose contents, and a decrease in the lignin content in the fibres.

The biochemical data were confirmed by the IR analysis of the fibres. The integral intensities of the successive bands were assessed and differences in the cellulose, pectin, hemicellulose and lignin contents were found. The bands responsible for hydrogen bonds and thus polymer arrangement were also analysed. Fibres from the transgenic B14 line were characterised by a rise in band intensity in the 3000 to $3600 \mathrm{~cm}^{-1}$ range, resulting from different conformations of the intra- and intermolecular hydrogen bonds in the cellulose. Also, the integral intensity of the $1236 \mathrm{~cm}^{-1}$ band was higher for B14 flax, suggesting an increase in the number of hydrogen bonds in the cellulose. Thus, the overexpression of the $\beta$-1,3-glucanase gene results in changes to the cellulose polymer organization, namely their closer packing in the fibres. One possible reason for the comparable fibre strength of the control and transgenic plants was the only slight change in the cellulose content. However, the reduced level of lignin affects the elastic properties of the fibre. The flexibility of fibres from the B14 line was elevated, as indicated by the lower Young's modulus. Additionally, lignin plays a very important role during fungal infection. It is known that an increase in lignin content gives a higher resistance to fungal attacks $[39,40]$. However, some studies yielded results that indicate that

Table 2 Phenolic compound contents in the cell wall fractions

\begin{tabular}{|c|c|c|c|c|c|c|c|}
\hline \multicolumn{8}{|c|}{$\mu \mathrm{g} / \mathrm{g} D W$} \\
\hline Fraction & & Vanillic acid & Vanillin & Coumaric acid & Syringic aldehyde & Ferulic acid & Vitexin \\
\hline \multirow[t]{2}{*}{ WSF } & Nike & $0.360 \pm 0.048$ & $0.108 \pm 0.028$ & $0.169 \pm 0.065$ & $0.152 \pm 0.052$ & $0.744 \pm 0.142$ & $0.757 \pm 0.014$ \\
\hline & B14 & $0.260 \pm 0.007$ & $0.150 \pm 0.045$ & $0.103 \pm 0.036$ & $0.09 \pm 0.013$ & $0.811 \pm 0.336$ & $0.930 \pm 0.322$ \\
\hline \multirow[t]{2}{*}{ CSF } & Nike & $0.071 \pm 0.003$ & $0.009 \pm 0.001$ & $0.038 \pm 0.004$ & $0.016 \pm 0.003$ & $0.162 \pm 0.006$ & $0.213 \pm 0.014$ \\
\hline & B14 & $0.104 \pm 0.032$ & $0.016 \pm 0.003^{*}$ & $0.055 \pm 0.011$ & $0.032 \pm 0.018$ & $0.295 \pm 0.055^{*}$ & $0.326 \pm 0.053^{*}$ \\
\hline \multirow[t]{2}{*}{ NSF } & Nike & $0.258 \pm 0.021$ & $0.034 \pm 0.009$ & $0.150 \pm 0.021$ & $0.055 \pm 0.009$ & $0.635 \pm 0.021$ & $1.085 \pm 0.085$ \\
\hline & B14 & $0.201 \pm 0.014^{*}$ & $0.043 \pm 0.008$ & $0.12 \pm 0.014$ & $0.042 \pm 0.003^{*}$ & $0.622 \pm 0.012$ & $1.022 \pm 0.074$ \\
\hline \multirow[t]{2}{*}{ K1SF } & Nike & $1.771 \pm 0.115$ & $1.196 \pm 0.240$ & $0.431 \pm 0.041$ & $1.212 \pm 0.071$ & $2.306 \pm 0.176$ & $3.349 \pm 0.270$ \\
\hline & B14 & $1.886 \pm 0.530$ & $1.917 \pm 0.505$ & $0.593 \pm 0.032^{* *}$ & $0.895 \pm 0.11^{*}$ & $2.925 \pm 0.281^{*}$ & $4.044 \pm 0.361^{*}$ \\
\hline \multirow[t]{2}{*}{ K4SF } & Nike & $0.477 \pm 0.286$ & $0.079 \pm 0.01$ & $0.046 \pm 0.012$ & $0.116 \pm 0.048$ & $0.145 \pm 0.050$ & $0.185 \pm 0.047$ \\
\hline & B14 & $1.597 \pm 0.199^{*}$ & $0.336 \pm 0.034^{* *}$ & $0.127 \pm 0.009^{* *}$ & $0.370 \pm 0.045^{* *}$ & $0.563 \pm 0.073^{* *}$ & $0.256 \pm 0.034$ \\
\hline
\end{tabular}

UPLC determination of the vanillic acid, coumaric acid, ferulic acid, vanillin, syringic aldehyde and vitexin contents in the cell wall fractions (WSF - water-soluble fraction, CSF - CDTA-soluble fraction, NSF - $\mathrm{Na}_{2} \mathrm{CO}_{3}$-soluble fraction, $\mathrm{K} 1 \mathrm{SF}-1 \mathrm{M} \mathrm{KOH}$-soluble fraction and $\mathrm{K} 4 \mathrm{SF}-4 \mathrm{M} \mathrm{KOH}$-soluble fraction) for fibres from transgenic flax line B14 and non-transgenic control flax Nike. Analyses were performed as described in the Methods section. Data represents the mean values \pm SD from three independent experiments. The significance of the differences between the means was determined using Student's $t$ test $\left(^{*}-\mathrm{P}<0.05,{ }^{* *}-\mathrm{P}<0.01\right)$. 
Table 3 Molar phenolic compound content relative to monosaccharide content in cell wall fractions

\begin{tabular}{|c|c|c|c|c|c|c|c|c|}
\hline \multicolumn{9}{|c|}{ Mmol of phenolic / $100 \mathrm{~mol}$ monosaccharide in cell wall fractions } \\
\hline Fraction & & Vanillic acid & Vanillin & Coumaric acid & Syringic aldehyde & Ferulic acid & Vitexin & Sum of phenolic compounds \\
\hline \multirow[t]{2}{*}{ WSF } & Nike & $2.95 \pm 0.38$ & $0.98 \pm 0.25$ & $1.42 \pm 0.54$ & $1.15 \pm 0.40$ & $5.28 \pm 1.01$ & $2.41 \pm 1.39$ & $14.18 \pm 1.14$ \\
\hline & B14 & $1.90 \pm 0.05^{*}$ & $1.21 \pm 0.69$ & $0.78 \pm 0.27$ & $0.61 \pm 0.09$ & $5.15 \pm 2.14$ & $2.65 \pm 0.92$ & $12.31 \pm 2.13$ \\
\hline \multirow[t]{2}{*}{ CSF } & Nike & $0.58 \pm 0.03$ & $0.08 \pm 0.01$ & $0.32 \pm 0.04$ & $0.12 \pm 0.02$ & $1.16 \pm 0.05$ & $0.69 \pm 0.04$ & $2.96 \pm 0.16$ \\
\hline & B14 & $0.68 \pm 0.21^{*}$ & $0.11 \pm 0.07$ & $0.37 \pm 0.07$ & $0.19 \pm 0.11$ & $1.66 \pm 0.31^{*}$ & $0.82 \pm 0.13$ & $3.84 \pm 0.82$ \\
\hline \multirow[t]{2}{*}{ NSF } & Nike & $2.51 \pm 0.32$ & $0.37 \pm 0.05$ & $1.50 \pm 0.08$ & $0.50 \pm 0.11$ & $5.35 \pm 0.85$ & $4.11 \pm 0.87$ & $14.34 \pm 2.07$ \\
\hline & $\overline{B 14}$ & $1.65 \pm 0.11^{*}$ & $0.39 \pm 0.06$ & $1.01 \pm 0.09^{*}$ & $0.32 \pm 0.08$ & $4.42 \pm 0.56$ & $3.26 \pm 0.90$ & $11.05 \pm 2.21$ \\
\hline \multirow[t]{2}{*}{ K1SF } & Nike & $11.30 \pm 0.74$ & $8.43 \pm 0.69$ & $2.82 \pm 0.27$ & $7.14 \pm 0.42$ & $12.74 \pm 0.98$ & $8.31 \pm 0.67$ & $50.75 \pm 3.75$ \\
\hline & B14 & $10.22 \pm 2.87$ & $11.48 \pm 3.03$ & $3.29 \pm 0.18^{*}$ & $4.48 \pm 0.55^{*}$ & $13.72 \pm 1.32^{*}$ & $8.52 \pm 0.76$ & $51.71 \pm 7.61$ \\
\hline \multirow[t]{2}{*}{ K4SF } & Nike & $7.27 \pm 2.36$ & $1.33 \pm 0.78$ & $0.71 \pm 0.19$ & $1.64 \pm 0.68$ & $1.92 \pm 0.66$ & $1.10 \pm 0.28$ & $13.98 \pm 5.87$ \\
\hline & B14 & $17.55 \pm 2.19^{* *}$ & $4.09 \pm 0.41^{* *}$ & $1.43 \pm 0.10^{* *}$ & $3.75 \pm 0.45^{*}$ & $5.36 \pm 0.70^{*}$ & $1.09 \pm 0.14$ & $33.28 \pm 4.05^{* *}$ \\
\hline \multirow[t]{2}{*}{ All fractions } & Nike & $24.62 \pm 5.56$ & $11.19 \pm 1.03$ & $6.77 \pm 0.93$ & $10.55 \pm 1.15$ & $26.46 \pm 1.85$ & $16.61 \pm 1.39$ & $96.20 \pm 8.98$ \\
\hline & $\overline{B 14}$ & $32.00 \pm 3.63$ & $17.28 \pm 2.41^{*}$ & $6.87 \pm 0.40$ & $9.35 \pm 0.65$ & $30.32 \pm 2.37$ & $16.36 \pm 1.51$ & $112.19 \pm 5.15^{*}$ \\
\hline
\end{tabular}

The amount of mmol of the studied phenolic compounds (vanillic acid, coumaric acid, ferulic acid, vanillin, syringic aldehyde and vitexin) to 100 mol of monosaccharides in the cell wall fractions (WSF - water-soluble fraction, $\mathrm{CSF}-\mathrm{CDTA}$-soluble fraction, $\mathrm{NSF}-\mathrm{Na}_{2} \mathrm{CO}_{3}$-soluble fraction, $\mathrm{K} 1 \mathrm{SF}-1 \mathrm{M} \mathrm{KOH}$-soluble fraction and K4SF $-4 \mathrm{M} \mathrm{KOH}$-soluble fraction) for fibres from transgenic flax line B14 and non-transgenic control flax Nike. Data represents the mean values \pm SD from three independent experiments. The significance of the differences between the means was determined using Student's $t$ test $\left({ }^{*}-\mathrm{P}<0.05\right.$, $\left.{ }^{* *}-\mathrm{P}<0.01\right)$.

plants are more resistant to fungal infection in spite of the reduced lignin content [41].

Significant changes in the pectin and hemicellulose contents observed in the fibres of the transgenic flax indicated the need for a detailed analysis of these polysaccharides, including an assessment of the monosaccharide composition and the phenolic acid content. The quantitative and qualitative contribution of pectin to the construction of the plant cell wall depends on the developmental stage [42] and the plant species $[43,44]$. The monosaccharide analysis revealed a higher content of galacturonic acid in all of the pectin fractions in the fibres from the transgenic flax, with the highest result in the CSF. Moreover, the fibres from B14 flax were characterised by a significant increase in the glucose content and an increase that was not always significant in the mannose and rhamnose content in all of the pectin fractions. Therefore, this genetic modification not only increased the quantity of pectin, but also changed its constituents. A similar tendency was observed in the

\section{Antioxidant activity}

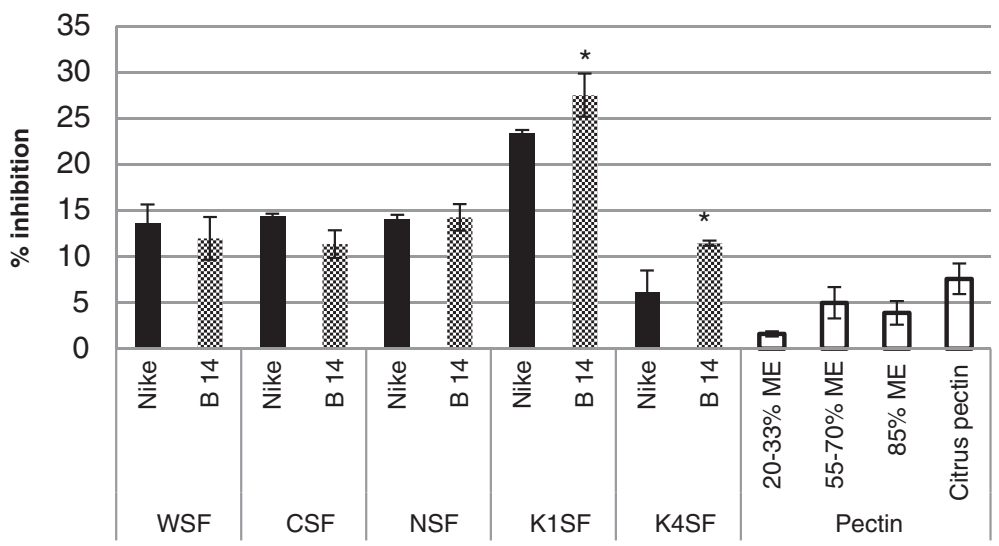

Figure 8 Scavenging activity of the cell wall fraction against $\mathrm{DPPH} \bullet$ radicals. The antioxidant potential was measured in the cell wall fractions (WSF - water-soluble fraction, CSF - CDTA-soluble fraction, NSF - $\mathrm{Na}_{2} \mathrm{CO}_{3}$-soluble fraction, $\mathrm{K} 1 \mathrm{SF}-1 \mathrm{M} \mathrm{KOH}$-soluble fraction and K4SF $4 \mathrm{M} \mathrm{KOH}$-soluble fraction) for fibres from transgenic flax line B14 (checked black bar) and non-transgenic control flax Nike (black bar) and compared with the values for commercially available citrus pectin with various ME values (20-33\%, 55-70\%, 85\%) and standard citrus pectin at a concentration of $5 \mathrm{mg} / \mathrm{ml}$ (white bars). Analyses were performed as described in the Methods section. Data represents the mean values \pm SD from three independent experiments. The significance of the differences between the means was determined using Student's $t$ test $\left({ }^{*}-\mathrm{P}<0.05\right)$. 
two hemicellulose fractions from the fibres. Significantly elevated contents of glucose and mannose in the K1SF and xylose in the K4SF but slightly reduced contents of rhamnose and galactose in both fractions were detected in the fibres from the transgenic plants. There is a marked galacturonic acid content reduction in the hemicellulose K1SF in the transgenic plants.

The changes in pectin and hemicellulose composition (and thus predicted structure) are even better illustrated when molar ratio of participating sugars were calculated giving a clearer picture of stoichiometry of forming units. What is mostly visible is statistically significant increased percentage of glucose and insignificant increase in galactouronic acid content with decrease of contribution of all other sugars in pectin fractions. In case of hemicelluloses increase in glucose percentage is observed only for K1SF fraction. The increase in the content of predominant monosaccharides is noteworthy, particularly the significantly elevated glucose content, which raises questions about the underlying molecular mechanism. We reasoned that $\beta$-1,3-glucanase hydrolyses $\beta$-1,3-glucans not only from the fungal cell wall, but also flax callose, an endogenic $\beta$-1,3-glucan. Since the level of callose was reduced in the fibres from transgenic line B14 relative to the levels for the control fibres, we speculate that the excess of glucose units could be used as substrate for the synthesis of other wall polymers (pectin or hemicellulose) [45]. The detailed analysis of the wall constituents revealed significant differences in the content of phenolic compounds bound with the pectin and hemicellulose fractions. Three phenolic acids (ferulic, vanillin and coumaric acid), two phenolic aldehydes (vanillin and syringic aldehyde) and one flavonoid (vitexin) were identified in the pectin fractions isolated from fibres. The total content of phenolic compounds in the fibres from the transgenic plants was about 26\% higher than in the fibres from the control plants. Of the wall fractions that were analysed, CSF and K4SF were characterised by a significant increase in the contents of most of the phenolic compounds. In K4SF, this is probably caused by the increase in xylose content in the transgenic flax fibres, as it was reported that phenolic acids bind preferentially to arabinoxylans $[46,47]$. In the remaining fractions, the quantities of particular compounds were different and depended on the fraction and the compound analysed.

The obtained results were reflected in the antioxidant properties of particular fractions. The highest antioxidant potential was shown by the K1SF of the fibres from the transgenic flax. It is worth noting that regardless of the similar quality of phenolic compounds in the WSF, NSF and K4SF, the hemicellulose fraction displayed the lowest ability to inhibit the reactive form $\mathrm{DPPH}$. It is speculated that besides the phenolic compound contents, the proper composition and structure of pectin might also affect the antioxidant properties [48]. It is interesting to note that the antioxidant activity of all of the wall fractions from flax fibres was statistically higher than that for commercially available pectin. The results confirmed that flax fibre pectin is potentially more beneficial than commercial citrus pectin and indicated the possibility of its biomedical application.

\section{Conclusion}

Fibres from flax plants overexpressing the $\beta$-1,3-glucanase gene have an altered wall biopolymer composition. The contents of particular polysaccharides (cellulose, hemicellulose and pectin) were higher, but reduced lignin content was also observed. A decrease in the content of callose, which is a substrate for $\beta$-1,3-glucanase, was also found. It is thus suggested that the glucose units released from the callose are redirected to the production of other polysaccharides. The increase in the contents of monosaccharides, the main component of hemicellulose, is accompanied by an accumulation of phenolic compounds in this fraction. The reason for this accumulation is unknown.

The antioxidant potential of the pectin fractions could be predicted from the amount of phenolic compounds. The fibres from transgenic plants showed a higher antioxidant potential than those from the control plants, which suggests their potential usefulness as biomedical products.

In summary, this study shows for the first time that the $\beta$-1,3-glucanase gene is involved in plant polysaccharide and lignin metabolism and establishes its benefits in the production of improved flax fibres.

\section{Methods}

\section{Plant material and retting}

Flax seeds (Linum usitatissimum L., fibrous cultivar Nike) were obtained from the flax and hemp collection of the Institute of Natural Fibres of Poland. Fourth-generation plants of the transgenic line and control flax were fieldcultivated in Wroclaw on a semi-technical scale during the 2010 growing season. The flax was harvested on the $107^{\text {th }}$ day of its growth. The field-grown plants were retted using the dew method, in which the plants are spread out in a field and left for at least 40 days. During this process, bacteria and fungi degrade the cell wall polysaccharides and middle lamella releasing the fibres from the stems [2]. The quantity of obtained fibres from whole straw is presented as \% fibres in the straw (Figure 1).

\section{Transgenic plants}

The plants were transformed using the plasmid pGAglubsens, containing cDNA encoding $\beta$-1,3-glucanase from potato (GenBank: AJ586575.1) under a 35S CaMV promoter and Nos terminator. Transgenic plants were pre-selected using PCR and selected using Western blot 
analysis. Three lines of transgenic plants were selected (B10, B11, B14) for in vitro testing. The B14 line was used for the field trials because it had the best productivity. None of the transgenic lines showed changes in plant height. The transgenic line B14 produced slightly more seeds than the non-transformed plants, while the transgenic lines B10 and B11 showed significant decreases in the yield of seeds [27].

\section{Infra-red spectrophotometry analysis}

Infra-red spectrometry was used to determine the chemical composition and molecular structure of the fibres from the transgenic and control flax plants. The spectra were measured at room temperature using a Biorad 575C FT-IR spectrometer. Data were collected over a spectral range from 50 to $4000 \mathrm{~cm}^{-1}$ with a resolution of $2 \mathrm{~cm}^{-1}$. In the mid infra-red part of this range, samples were prepared in a $\mathrm{KBr}$ pellet. In the far infra-red part of this range, samples were suspended in Nujol.

\section{Mechanical analysis of fibre}

Tensile tests of the retted fibres were conducted by means of a computer-driven Instron system (model 4452, High Wycombe, UK). The finest axially uniform $2.5-$ to $4.0-\mathrm{cm}$ long filaments were carefully extracted by hand from the fibre bundles. The ends of the samples were glued and sandwiched between small plastic sheets using a cyanoacrylate adhesive and were pinched within serrated grips connected both to a load cell of $10 \mathrm{~N}$ capacity and to the immovable part of the testing machine. The adhesive was spread out in a very thin layer and allowed to partially dry and solidify before the fibre ends were attached to the plastic pieces to avoid undesirable impregnation of the free filament part with cyanoacrylate. Samples of about 10-mm gauge length were extended at a crosshead speed of $1 \mathrm{~mm} / \mathrm{min}$. The exact gauge length was determined for each fibre to an accuracy of $0.01 \mathrm{~mm}$ at a tensile load of $5 \mathrm{cN}$. The load displacement curve was recorded and used to evaluate the fibre tensile parameters with Bluehill 2 Software (Instron Co.).

Stiffness, measured as Young' modulus, was calculated from the slope of a linear part of the load displacement curve $(\Delta \mathrm{F} / \Delta \mathrm{x})$, using the formula:

$$
E=\frac{\frac{\Delta F}{\Delta x}}{\frac{L}{A c w}}
$$

where $\mathrm{L}$ is the gauge length (corrected for each sample using Instron readings) and Acw is the effective cell wall cross-sectional area.

The maximum recorded load $\left(\mathrm{F}_{\max }\right)$ per initial crosssectional area of cell wall material (Acw) was used as a tensile strength measure:

$$
\sigma=\frac{F_{\max }}{A c w}
$$

The cross-sectional area of the cell wall material was evaluated using a gravimetric method $[49,50]$ and the formula:

$$
A c w=\frac{m}{L \cdot d c w}
$$

where $m$ is the weight of the fibre gauge length and $\mathrm{dcw}$ is the cell wall material density, assumed to equal 1540 $\mathrm{kg} \mathrm{m}^{-3}[51]$.

The energy to break (determined as the strain energy to maximum load) per unit mass of fibre sample and the relative extension at break were determined using Bluehill 2 software.

The sample weight within the gauge length, needed for the estimation of the cross-sectional area of the cell wall material, was determined soon after tensile measurements were completed, to an accuracy of $1 \mu \mathrm{g}$, using a highly precise microbalance (XP6, Mettler, Toledo).

\section{Cellulose content}

The cellulose content was determined using the colourimetric method with anthrone reagent, as described by Ververis [52]. $15 \mathrm{mg}$ dry, ground flax fibres were incubated with a mixture of nitric and acetic acid $(1: 8 \mathrm{v} / \mathrm{v})$ for $1 \mathrm{~h}$ at $100^{\circ} \mathrm{C}$ and then centrifuged $(5 \mathrm{~min}, 14000$ $\mathrm{rpm})$. The pellet was washed twice with water and then resuspended in $1 \mathrm{ml} 67 \% \mathrm{H}_{2} \mathrm{SO}_{4}$ (v/v). After mixing samples, cold anthrone reagent was added and the cellulose level in these samples was measured spectrophotometrically at $620 \mathrm{~nm}$. Commercially available cellulose after hydrolysis was used for the calibration curve.

\section{Lignin content}

The determination of the total lignin content was performed using the acetyl bromide method, as described Iiyama and Wallis [53]. $15 \mathrm{mg}$ dry, ground flax fibres were heated for $2 \mathrm{~h}$ at $100^{\circ} \mathrm{C}$, then $10 \mathrm{ml}$ water was added to each sample, and the samples were heated for $1 \mathrm{~h}$ at $65^{\circ} \mathrm{C}$ with mixing every $10 \mathrm{~min}$. Then the samples were filtered through a GF/A glass fibre filter and rinsed three times with each of the following solutions: water, ethanol, acetone and diethyl ether. The filters were placed in glass vials and heated overnight at $70^{\circ} \mathrm{C}$. After that, $25 \%$ acetyl bromide $(2.5 \mathrm{ml})$ in acetic acid was added and the vials were placed at $50^{\circ} \mathrm{C}$ for $2 \mathrm{~h}$. The cooled samples were mixed with $10 \mathrm{ml}$ of $2 \mathrm{~N}$ sodium hydroxide and $12 \mathrm{ml}$ of acetic acid. After incubating in RT overnight, the lignin content was measured at 280 $\mathrm{nm}$. Coniferyl alcohol was used to prepare a calibration curve. 
Isolation and fractionation of the cell wall polysaccharides The isolation and fractionation of the cell wall components was performed using a modified version of the method described by Manganaris [54] and Vincente [55].

Fibres from transgenic and non-transgenic flax $(1 \mathrm{~g}$ dry, ground plant tissue) were boiled in $96 \%$ ethanol for 30 min to inactivate the enzymes, extract the low molecular weight components and prevent autolysis. The material was filtered with a Whatman GF/C filter and then sequentially washed with $80 \%$ ethanol, chloroform: methanol $(1: 1 \mathrm{v} / \mathrm{v})$ and acetone, and allowed to dry at $37^{\circ} \mathrm{C}$ to yield an alcohol-insoluble residue (AIR).

All the AIR obtained from each sample was suspended in $20 \mathrm{ml}$ of water and then stirred at RT for $12 \mathrm{~h}$. After the centrifugation $\left(6000 \times \mathrm{g}, 4^{\circ} \mathrm{C}, 10 \mathrm{~min}\right)$ the pellet was washed with water and both supernatants were collected for water-soluble fraction (WSF) analysis. The remaining material was resuspended in $50 \mathrm{mM}$ CDTA (trans-1,2diaminocyclohexane-N,N,N,N-tetraacetic acid) at $\mathrm{pH} 6.5$ and stirred (RT, $12 \mathrm{~h}$ ). After the centrifugation and wash (as above), the extracted solutions were collected and designated the CDTA-soluble fraction (CSF). The pellet was resuspended in $50 \mathrm{mM} \mathrm{Na} \mathrm{CO}_{3}$ with $20 \mathrm{mM}$ $\mathrm{NaBH}_{4}$, stirred at $4^{\circ} \mathrm{C}$ for $12 \mathrm{~h}$ and washed, and then supernatants were neutralised with glacial acetic acid. These samples were designed the $\mathrm{Na}_{2} \mathrm{CO}_{3}$-soluble fraction (NSF). The remaining pelleted material was resuspended in $1 \mathrm{M} \mathrm{KOH}$ with $20 \mathrm{mM} \mathrm{NaBH}_{4}$, stirred at RT for $12 \mathrm{~h}$ and washed, and then supernatants were neutralised with $\mathrm{HCl}$ to yield the $1 \mathrm{M} \mathrm{KOH}$-soluble fraction (K1SF). The same activity was performed with $4 \mathrm{M}$ $\mathrm{KOH}$ to obtain the $4 \mathrm{M} \mathrm{KOH}$-soluble fraction (K4SF). Supernatants from the CSF, NSF, K1SF and K4SF were extensively dialysed against water (with a $3.5-\mathrm{kDa}$ cut off) and all of the fractions were additionally lyophilised before use.

\section{Uronic acid measurement}

The content of pectin was determined using the biphenyl method [56] after hydrolysis of the polysaccharides in sulphuric acid [57]. The samples were suspended in $0.1 \mathrm{ml}$ sulphuric acid and stirred in an ice bath for $5 \mathrm{~min}$. Sequentially, $0.1 \mathrm{ml}$ sulphuric acid, $0.05 \mathrm{ml}$ water, $0.05 \mathrm{ml}$ water and $0.7 \mathrm{ml}$ water were added, with stirring between additions. The diluted material was centrifuged for $10 \mathrm{~min}$ at $2000 \times \mathrm{g}$ at RT, and $0.1 \mathrm{ml}$ of the supernatant was taken and added to a 10- $\mu \mathrm{l} 4 \mathrm{M}$ sulphamic acid/potassium sulphamate solution at $\mathrm{pH}$ 1.6. Then $0.6 \mathrm{ml}$ of $75 \mathrm{mM}$ $\mathrm{Na}_{2} \mathrm{~B}_{4} \mathrm{O}_{7}$ in sulphuric acid was added for the reaction. The samples were shaken and incubated at $100^{\circ} \mathrm{C}$ for $20 \mathrm{~min}$. After cooling, $20 \mu \mathrm{l}$ of m-hydroxy-biphenyl $(0.15 \%)$ in $0.5 \% \mathrm{NaOH}$ was added to each sample, and they were incubated at RT for $10 \mathrm{~min}$. The pectin content was measured with a spectrophotometer at $525 \mathrm{~nm}$. Galacturonic acid was used for the calibration curve.

\section{Monosaccharide identification by UPLC}

The hydrolysis of polysaccharides, derivatization procedure and UPLC analysis were performed using a modified version of the method describe by Lv [58] and Yang [59]. The lyophilized tissue samples $(10 \mathrm{mg})$ were hydrolysed with $4 \mathrm{M}$ TFA $(500 \mathrm{ml})$ for $8 \mathrm{~h}$ at $110^{\circ} \mathrm{C}$, and then cooled and centrifuged ( $5 \mathrm{~min}, 1000 \mathrm{rpm}, \mathrm{RT}$ ). The pellet was discarded and the supernatant was dried under nitrogen and then dissolved in distilled water $(1 \mathrm{ml})$.

In order to determine their monosaccharide composition, the samples $(50 \mu \mathrm{l})$ were derivatised by incubation for $60 \mathrm{~min}$ at $70^{\circ} \mathrm{C}$ with $0.3 \mathrm{M} \mathrm{NaOH}(50 \mu \mathrm{l})$ and $0.5 \mathrm{M}$ PMP in methanol $(50 \mu \mathrm{l})$. After cooling, $0.3 \mathrm{M} \mathrm{HCl}$ $(50 \mu \mathrm{l})$ was added to each sample and they were washed three times with chloroform. Each sample was filtered before UPLC analysis.

The samples were analysed on a Waters Acquity UPLC system with a 2996 PDA detector, using Acquity UPLC column BEH C18, $1.0 \times 100 \mathrm{~mm}, 1.7 \mu \mathrm{m}$. The mobile phase was $\mathrm{A}=50 \mathrm{mM} \mathrm{CH}_{3} \mathrm{COONa}$, pH 6.3 with $0.04 \%$ TEA and $\mathrm{B}=$ acetonitrile with $0.04 \% \mathrm{TEA}$, in a gradient flow: $1 \mathrm{~min}$ at $96 \% \mathrm{~A} / 4 \% \mathrm{~B} ; 5-11 \mathrm{~min}$ gradient to $89 \%$ $\mathrm{A} / 11 \% \mathrm{~B} ; 12-13$ min gradient to $0 \% \mathrm{~A} / 100 \% \mathrm{~B}$; and 14 min gradient to $96 \% \mathrm{~A} / 4 \% \mathrm{~B}$ with a $0.05-\mathrm{ml} / \mathrm{min}$ flow rate. The content was measured at $250 \mathrm{~nm}$.

\section{Total pectin and total hemicellulose contents}

The content of total pectin was estimated as the sum of the uronic acids and other monosaccharides from the three pectin fractions (WSF, CSF and NSF).

The total hemicellulose content was calculated in the same way for the other two fractions (K1SF and K4SF).

\section{Callose content}

The determination of the callose content in the flax fibres was performed using a modification of a method described by Hirano [60]. $20 \mathrm{mg}$ dry, ground flax fibres were washed once with $96 \%$ ethanol and three times with $20 \%$ ethanol. Then, $1 \mathrm{ml}$ of $1 \mathrm{M} \mathrm{NaOH}$ was added to the washed tissue, and to solubilise the callose, the tubes were heated at $80^{\circ} \mathrm{C}$ for $15 \mathrm{~min}$. After the centrifugation (15 $\mathrm{min}, 10000 \times \mathrm{g}$ ), the supernatant was ready for the callose determination. $0.2 \mathrm{ml}$ of supernatant, $0.4 \mathrm{ml}$ of $0.1 \%(\mathrm{w} / \mathrm{v})$ aniline blue, $0.21 \mathrm{ml}$ of $1 \mathrm{M} \mathrm{HCl}$ and $0.59 \mathrm{ml}$ of $1 \mathrm{M}$ glycine- $\mathrm{NaOH}$ buffer ( $\mathrm{pH}$ 9.5) were mixed and incubated for $20 \mathrm{~min}$ at $50^{\circ} \mathrm{C}$, and then $30 \mathrm{~min}$ at room temperature. The callose content was quantified spectrofluorometrically at excitation and emission wavelengths of 393 and $484 \mathrm{~nm}$, respectively. Curdlan ( $\beta$-1,3-glucan) was used to prepare a calibration curve. 


\section{Phenolic compound extraction and measurement by UPLC}

The lyophilized samples (20-100 mg) from each fraction of the cell wall were extracted three times with methanol using an ultrasonic bath (15 min). After centrifugation (5 min, $5000 \mathrm{rpm}, \mathrm{RT}$ ), the supernatant was collected and the pellet was hydrolysed using $2 \mathrm{M} \mathrm{NaOH}(2 \mathrm{ml})$ in the dark. Then, the $\mathrm{pH}$ was adjusted to 3.0, and the samples were extracted three times with ethyl acetate and centrifuged ( $1 \mathrm{~min}, 5000 \mathrm{rpm}, \mathrm{RT}$ ). The supernatant was dried, the pellet was resuspended in methanol (0.2 $\mathrm{ml}$ ) and the samples were analysed on a Waters Acquity UPLC system with a 2996 PDA detector, using an Acquity UPLC column BEH C18, $2.1 \times 100 \mathrm{~mm}, 1.7 \mu \mathrm{m}$. The mobile phase was $\mathrm{A}=0.1 \%$ formic acid and $\mathrm{B}=$ acetonitrile, in a gradient flow: $1 \mathrm{~min}$ at $95 \% \mathrm{~A} / 5 \%$ $\mathrm{B} ; 12$ min gradient to $70 \% \mathrm{~A} / 30 \% \mathrm{~B} ; 15$ min gradient to $0 \% \mathrm{~A} / 100 \% \mathrm{~B}$; and $17 \mathrm{~min} 95 \% \mathrm{~A} / 5 \% \mathrm{~B}$ with a $0.1 \mathrm{ml} /$ min flow rate. The detection of coumaric and ferulic acid, syringic aldehyde, vanillin and vitexin was done at $320 \mathrm{~nm}$ and that of vanillic acid at $280 \mathrm{~nm}$.

\section{Antioxidant activity}

The antioxidant activity was assessed as described by Brand-Williams with some modifications [61]. $10 \mathrm{mg}$ of lyophilised samples from each cell wall fraction were resuspended in $1 \mathrm{ml}$ of water. In a similar way, standards of pectin with different degrees of methylation were prepared. A $1 \mathrm{ml}$ solution of $0.1 \mathrm{mM}$ DPPH (2,2-diphenyl1-picrylhydrazyl) in water:methanol (1:1) was mixed with $50 \mu \mathrm{l}$ of sample. After $6 \mathrm{~h}$, the absorbance was measured at $515 \mathrm{~nm}$. Ferulic acid was used as a positive control.

The inhibition of DPPH • radicals of the cell wall fraction was calculated according to the equation:

$$
(\%) \text { inhibition }=\left[1-\left(A_{\text {sample }} 515 \mathrm{~nm} / A_{\text {control }} 515 \mathrm{~nm}\right)\right] \times 100
$$

\section{Statistical analysis}

All of the experiments were independently repeated at least three times. The results are presented as the averages of independent replicates \pm standard deviations. Statistical analyses were performed using Statistica 7 software (Statsoft, USA). The significance of the differences between the means was determined using Student's t test.

\section{Abbreviations \\ CSF: CDTA-soluble fraction; DPPH: 2.2-diphenyl-1-picrylhydrazyl; GalAc: Galacturonic acid; K1SF: 1 M KOH-soluble fraction; K4SF: $4 \mathrm{M-KOH}$ soluble fraction; NSF: $\mathrm{Na}_{2} \mathrm{CO}_{3}$-soluble fraction; WSF: Water-soluble fraction.}

\section{Competing interests}

The authors declare that they have no competing interests.

\section{Authors' contributions}

WW performed all the biochemical experiments and statistical analyses and wrote the manuscript. AK designed the experiments, carried out the UPLC analysis and participated in writing the manuscript. LD performed the infrared spectrophotometry analysis and participated in writing the IR-related section of the manuscript. JH participated in the infra-red spectrophotometry analysis. JŻ performed the mechanical analysis. JS participated in study design and coordination. All of the authors read and approved the final version of the manuscript.

\section{Acknowledgements}

This paper is supported by grants No 178676 from National Center for Research and Development (NCBiR), Poland and 2012/06/A/NZ1/00006 from National Science Center (NCN). The work of Wioleta Wojtasik is co-financed by the European Union as part of the European Social Fund.

\section{Author details}

${ }^{1}$ Faculty of Biotechnology, University of Wrocław, Przybyszewskiego 63/77, 51-148, Wrocław, Poland. ${ }^{2}$ Department of Bioorganic Chemistry, Institute of Chemistry and Food Technology, Faculty of Economics and Engineering, University of Economics, Komandorska 118/120, 50-345, Wrocław, Poland. ${ }^{3}$ Institute of Low Temperatures and Structure Research, Polish Academy of Sciences, Okolna 2, 50-422, Wrocław, Poland. ${ }^{4}$ Faculty of Biotechnology, Centre of Applied Biotechnology and Basic Sciences, Rzeszów University, Rzeszów, Poland. 'Linum Fundation, Stabłowicka 149-147, 54-066 Wroclaw, Poland.

Received: 19 September 2012 Accepted: 4 February 2013

Published: 9 February 2013

\section{References}

1. Czemplik M, Szopa J: Optimizing biomedical and industrial products development based on flax. Perspectives in Agriculture, Veterinary Science, Nutrition and Natural Resources 2009, 4(62):1-10.

2. Henriksson G, Akin DE, Hanlin RT, Rodriguez C, Archibald DD, Rigsby LL, Eriksson $\mathrm{KL}$ : Identification and retting efficiencies of fungi isolated from dew-retted flax in the United States and Europe. Appl Environ Microbiol 1997, 63(10):3950-3956.

3. Ridley BL, O'Neill MA, Mohnen D: Pectins: structure, biosynthesis, and oligogalacturonide-related signaling. Phytochemistry 2001, 57(6):929-967.

4. Vorwerk S, Somerville S, Somerville C: The role of plant cell wall polysaccharide composition in disease resistance. Trends Plant Sci 2004, 9(4):203-209.

5. Houben K, Jolie RP, Fraeye I, Van Loey AM, Hendrickx ME: Comparative study of the cell wall composition of broccoli, carrot, and tomato: structural characterization of the extractable pectins and hemicelluloses. Carbohydr Res 2011, 346(9):1105-1111.

6. Lorenc-Kukula K, Amarowicz R, Oszmianski J, Doermann P, Starzycki M, Skala J, Żuk M, Kulma A, Szopa J: Pleiotropic effect of phenolic compounds content increases in transgenic flax plant. J Agric Food Chem 2005, 53(9):3685-3692.

7. Lorenc-Kukula K, Zuk M, Kulma A, Czemplik M, Kostyn K, Skala J, Starzycki M, Szopa J: Engineering flax with the GT Family 1 Solanum sogarandinum glycosyltransferase SsGT1 confers increased resistance to Fusarium infection. J Agric Food Chem 2009, 57(15):6698-6705.

8. Czuj T, Żuk M, Starzycki M, Amir R, Szopa J: Engineering increases in sulfur amino acid contents in flax by overexpressing the yeast Met25 gene. Plant Sci 2009, 177(6):584-592.

9. Shetty NP, Jensen JD, Knudsen A, Finnie C, Geshi N, Blennow A, Collinge $D B$, Jørgensen HJL: Effects of $\beta$-1,3-glucan from Septoria tritici on structural defence responses in wheat. J Exp Bot 2009, 60(15):4287-4300.

10. Sarowar S, Kim YJ, Kim EN, Kim KD, Hwang BK, Islam R, Shin JS: Overexpression of a pepper basic pathogenesis-related protein 1 gene in tobacco plants enhances resistance to heavy metal and pathogen stresses. Plant Cell Rep 2005, 24(4):216-224.

11. Iqbal MM, Nazir F, Ali S, Asif MA, Zafar Y, lqbal J, Ali GM: Over expression of rice chitinase gene in transgenic peanut (Arachis hypogaea L.) improves resistance against leaf spot. Mol Biotechnol 2012, 50(2):129-136.

12. Meins FJ, Neuhaus JM, Sperisen C, Ryals J: The primary structure of plant pathogenesis-related glucanohydrolases and their genes. In Genes Involved in Plant Defense. 1st edition. Edited by Boller T, Meins F Jr. Vienna: Springer-Verlag; 1992:245-282.

13. Datta SK, Muthukrishnan S: Pathogenesis-Related Proteins in Plants. Washington: CRC Press; 1999 
14. Heyn ANA: Glucanase activity in coleoptiles of Avena. Arch Biochem Biophys 1969, 132(2):442-449.

15. Fulcher RG, McCully ME, Setterfield G, Sutherland J: $\beta-1,3-G l u c a n s$ may be associated with cell plate formation during cytokinesis. Can J Bot 1976, 54(5-6):539-542.

16. Hinton MD, Pressey R: Glucanases in fruits and vegetables. J Am Soc Hortic Sci 1980, 105(4):499-502.

17. Ori N, Sessa G, Lotan T, Himmelhoch S, Fluhr R: A major stylar matrix polypeptide (sp41) is a member of the pathogenesis-related proteins superclass. EMBO J 1990, 9(11):3429-36.

18. Meikle PJ, Bonig I, Hoogenraad NJ, Clarke AE, Stone BA: The location of $(1-3)$ - $\beta$-glucans in the walls of pollen tubes of Nicotiana alata using a (1-3)- $\beta$-glucanspecific monoclonal antibody. Planta 1991, 185:1-8.

19. Krabel D, Eschrich W, Wirth S, Wolf G: Callase-(1,3- $\beta$-d-glucanase) activity during spring reactivation in deciduous trees. Plant Sci 1993, 93(1-2):19-23.

20. Bucciaglia PA, Smith AG: Cloning and characterization of Tag 1, a tobacco anther beta-1,3-glucanase expressed during tetrad dissolution. Plant Mol Biol 1994, 24(6):903-914.

21. Helleboid S, Chapman A, Hendriks T, Inze D, Vasseur J, Hilbert JL: Cloning of beta-1,3-glucanases expressed during Cichorium somatic embryogenesis. Plant Mol Biol 2000, 42(2):377-386.

22. Buchner $P$, Rochat $C$, Wuillème $S$, Boutin J-P: Characterization of a tissue-specific and developmentally regulated $\beta$-1,3-glucanase gene in pea (Pisum sativum). Plant Mol Biol 2002, 49(2):171-186.

23. Matsushima $\mathrm{H}$ : Development of beta-1,3-glucanase activity in germinated tomato seeds. J Exp Bot 2000, 51(349):1381-1387.

24. Neale AD, Wahleithner JA, Lund M, Bonnett HT, Kelly A, Meeks-Wagner DR, Peacock WJ, Dennis ES: Chitinase, beta-1,3-glucanase, osmotin, and extensin are expressed in tobacco explants during flower formation. Plant Cell 1990, 2(7):673-684.

25. Akiyama T, Pillai MA, Sentoku N: Cloning, characterization and expression of OsGLN2, a rice endo-1,3-beta-glucanase gene regulated developmentally in flowers and hormonally in germinating seeds. Planta 2004, 220(1):129-139.

26. Chen XY, Kim JY: Callose synthesis in higher plants. Plant Signal Behav 2009, 4(6):489-492.

27. Wróbel-Kwiatkowska M, Lorenc-Kukula K, Starzycki M, Oszmiański J, Kepczyńska E, Szopa J: Expression of $\beta$-1,3-glucanase in flax causes increased resistance to fungi. Physiol Mol Plant Pathol 2004, 65(5):245-256.

28. Lerouxel O, Cavalier DM, Liepman AH, Keegstra K: Biosynthesis of plant cell wall polysaccharides - a complex process. Curr Opin Plant Biol 2006, 9(6):621-630.

29. Amthor JS: Efficiency of lignin biosynthesis: a quantitative analysis. Ann Bot 2003, 91(6):673-695.

30. Jähn A, Schröder MW, Füting M, Schenzel K, Diepenbrock W: Characterization of alkali treated flax fibres by means of FT Raman spectroscopy and environmental scanning electron microscopy. Spectrochim Acta A Mol Biomol Spectrosc 2002, 58(10):2271-2279.

31. Tsuboi M: Infrared spectrum and crystal structure of cellulose. J Polymer Sci 1957, 25(109):159-171.

32. Liang $\mathrm{CY}$, Marchessault $\mathrm{RH}$ : Infrared spectra of crystalline polysaccharides. II. Native celluloses in the region from 640 to $1700 \mathrm{~cm}^{-1}$. J Polymer Sci 1959, 39(135):269-278.

33. Himmelsbach DS, Khalili S, Akin DE: The use of FT-IR microspectroscopic mapping to study the effects of enzymatic retting of flax (Linum usitatissimum L) stems. J Sci Food Agric 2002, 82(7):685-696.

34. Schwanninger M, Rodrigues JC, Pereira $H$, Hinterstoisser B: Effects of short-time vibratory ball milling on the shape of FT-IR spectra of wood and cellulose. Vib Spectrosc 2004, 36(1):23-40.

35. Carrillo F, Colom X, Suñol JJ, Saurina J: Structural FTIR analysis and thermal characterisation of lyocell and viscose-type fibres. Eur Polym J 2004, 40(9):2229-2234

36. Eichhorn SJ, Sirichaisit J, Young RJ: Deformation mechanisms in cellulose fibres, paper and wood. J Mater Sci 2001, 36(13):3129-3135.

37. Dai $D$, Fan M: Investigation of the dislocation of natural fibres by Fourier-transform infrared spectroscopy. Vib Spectrosc 2011, 55(2):300-306.

38. Gałat A: Study of the Raman scattering and infrared absorption spectra of branched polysaccharides. Acta Biochim Pol 1980, 27(2):135-142.

39. Xu L, Zhu L, Tu L, Liu L, Yuan D, Jin L, Long L, Zhang X: Lignin metabolism has a central role in the resistance of cotton to the wilt fungus
Verticillium dahliae as revealed by RNA-Seq-dependent transcriptional analysis and histochemistry. J Exp Bot 2011, 62(15):5607-5621.

40. Shi H, Liu Z, Zhu L, Zhang C, Chen Y, Zhou Y, Li F, Li X: Overexpression of cotton (Gossypium hirsutum) dirigent1 gene enhances lignification that blocks the spread of Verticillium dahliae. Acta Biochim Biophys Sin (Shanghai) 2012, 44(7):555-564.

41. Bart RS, Chern M, Vega-Sánchez ME, Canlas P, Ronald PC: Rice Snl6, a Cinnamoyl-CoA Reductase-Like Gene Family Member, Is Required for $\mathrm{NH} 1$-Mediated Immunity to Xanthomonas oryzae pv. oryzae. PLoS Genet 2010, 6(9):e1001123.

42. Stolle-Smits T, Beekhuizen JG, Kok MT, Pijnenburg M, Recourt K, Derksen J, Voragen AG: Changes in cell wall polysaccharides of green bean pods during development. Plant Physiol 1999, 121(2):363-372

43. Prabasari I, Pettolino F, Liao M-L, Bacic A: Pectic polysaccharides from mature orange (Citrus sinensis) fruit albedo cell walls: Sequential extraction and chemical characterization. Carbohydr Polym 2011, 84(1):484-494.

44. Aboughe-Angone $S$, Nguema-Ona E, Ghosh P, Lerouge P, Ishii T, Ray B, Driouich A: Cell wall carbohydrates from fruit pulp of Argania spinosa: structural analysis of pectin and xyloglucan polysaccharides. Carbohydr Res 2008, 343(1):67-72.

45. Dhugga KS: Biosynthesis of non-cellulosic polysaccharides of plant cell walls. Phytochemistry 2012, 74(0):8-19

46. Bunzel M, Allerdings E, Sinwell V, Ralph J, Steinhart H: Cell wall hydroxycinnamates in wild rice (Zizania aquatica L.) insoluble dietary fibre. European Food Research and Technology 2002, 214(6):482-488.

47. Ishii T: Structure and functions of feruloylated polysaccharides. Plant Sci 1997, 127(2):111-127.

48. Chen $H$, Zhang M, Xie B: Quantification of uronic acids in tea polysaccharide conjugates and their antioxidant properties. J Agric Food Chem 2004, 52(11):3333-3336.

49. Sommerville PJ: Fundamental principles of fibre diameter measurements., vol. Part 5. AWTA Ltd Newsletter; 2002.

50. Saville BP: Physical testing of textiles. Cambridge: Woodhead Publishing 1999.

51. Baley C: Analysis of the flax fibres tensile behaviour and analysis of the tensile stiffness increase. Composites Part A: Applied Science and Manufacturing 2002, 33(7):939-948.

52. Ververis C, Georghiou K, Christodoulakis N, Santas P, Santas R: Fiber dimensions, lignin and cellulose content of various plant materials and their suitability for paper production. Ind Crop Prod 2004, 19(3):245-254.

53. liyama K, Wallis AFA: Determination of lignin in herbaceous plants by an improved acetyl bromide procedure. J Sci Food Agric 1990, 51(2):145-161.

54. Manganaris GA, Vicente AR, Crisosto $\mathrm{CH}$, Labavitch JM: Cell wall modifications in chilling-injured plum fruit (Prunus salicina). Postharvest Biology and Technology 2008, 48(1):77-83.

55. Vicente AR, Powell A, Greve LC, Labavitch JM: Cell wall disassembly events in boysenberry (Rubus idaeus L. x Rubus ursinus Cham. \& Schldl.) fruit development. Functional plant biology: FPB 2007, 34(7):614-623.

56. Blumenkrantz N, Asboe-Hansen G: New method for quantitative determination of uronic acids. Anal Biochem 1973, 54(2):484-489.

57. Ahmed AER, Labavitch JM: A simplified method for accurate determination of cell wall uronide content. J Food Biochem 1978, 1(4):361-365.

58. Lv $Y$, Yang $X$, Zhao $Y$, Ruan $Y$, Yang $Y$, Wang Z: Separation and quantification of component monosaccharides of the tea polysaccharides from Gynostemma pentaphyllum by HPLC with indirect UV detection. Food Chem 2009, 112(3):742-746.

59. Yang $X$, Zhao Y, Wang Q, Wang H, Mei Q: Analysis of the monosaccharide components in Angelica polysaccharides by high performance liquid chromatography. Anal Sci 2005, 21(10):1177-1180.

60. Hirano Y, Pannatier EG, Zimmermann S, Brunner I: Induction of callose in roots of Norway spruce seedlings after short-term exposure to aluminum. Tree Physiol 2004, 24(11):1279-1283

61. Brand-Williams W, Cuvelier ME, Berset C: Use of a free radical method to evaluate antioxidant activity. LWT- Food Sci Technol 1995, 28(1):25-30

doi:10.1186/1472-6750-13-10

Cite this article as: Wojtasik et al.: Fibres from flax overproducing $\beta-1,3$ glucanase show increased accumulation of pectin and phenolics and thus higher antioxidant capacity. BMC Biotechnology 2013 13:10. 